\title{
Explosion Characteristics of a Volatile Explosive
}

\author{
Saad A. EL-Sayed*
}

Mechanical Power Engineering Department Zagazig University-El-Sharkia, Egypt

\begin{abstract}
Thermal explosion of volatile energetic materials has been investigated based upon the thermal explosion theory of a gaseous mixture. The critical and transition condition expressions for the thermal explosion of these materials are obtained. The analytical solutions not only deal with the steady-state solution but also cover the unsteady state solution. The different cases and different parameters which affect the critical conditions are investigated in details. Also the numerical solution of the energy equation is offered to give the different families of temperature - time histories. The relation between the critical parameters as ignition timing, ignition temperature, Semenov number and others with different boundary conditions is offered.
\end{abstract}

Keywords: Thermal explosion, volatile explosive materials, analytical and numerical solutions, critical and transition conditions, ignition critical parameters.

\section{INTRODUCTION}

The theory of the thermal explosion of volatile energetic materials (liquid explosives widely used in rocket engineering, such as highly concentrated $\mathrm{H}_{2} \mathrm{O}_{2}$, hydrazine, ammonium per chlorate and nitrate, gun propellants, in construction and mining, in emergency escape devices and automobile air bags, and in material synthesis and others) is important. The irreversible decomposition of the condensed phases of these materials is accompanied by reagent evaporation and the saturation of gaseous reaction product with reagent vapor. This effect should be taken into consideration when analyzing reaction-related processes. The theoretical and experimental studies of thermal decomposition and explosion of volatile explosives have been investigated by [1-3]. A thermal decomposition of energetic materials (NTO and Organic Peroxide) was investigated experimentally by [4-6] studied the techniques of thermal analysis, in general and differential scanning calorimetry to provide the ways of examining such substance under relatively safe conditions was studied by [7]. The thermal decomposition of the highly energetic materials was investigated by the TGA (Thermogravimetric analysis) and DSC (differential scanning calorimetry). A calorimetric measurement for the thermal decomposition of energetic material using APTAC was offered by [8]. A thermal decomposition mechanism and kinetic parameters from 50 to $500{ }^{\circ} \mathrm{C}$ were studied under a linear heating rate of potassium with DSC by [9]. Combustion of volatile condensed systems behind the stability limit of the stationary regime was studied numerically by [10]. Also, the thermal behavior and kinetic parameters of the exothermic decomposition reaction to the title compound were investigated by [11].

*Address correspondence to this author at the Mechanical Power Engineering Department Zagazig University-El-Sharkia, Egypt;

Tel/Fax: 0020233386905-009654843143; E-mail: saada53@yahoo.com
In this work, the critical and transition conditions of the explosion of the volatile energetic materials through the analytical solution to the problem was introduced. The numerical solution of the unsteady state equation to the problem was offered. The relation between the critical parameters was also presented. The effect of evaporation of the volatile materials as compared with the non-volatile materials on the critical conditions was shown.

\section{THE GOVERNING EQUATIONS}

Let us consider the kinetics of the reduction in the weight of a liquid at a constant temperature of a thermogravimetric experiment. Under quasi-steady conditions, the total rate of the weight reduction can be expressed as the sum of the gas formation and evaporation rates,

$-\frac{d m}{d t}=\frac{d m_{g}}{d t}\left(1+\frac{d m_{v}}{d m_{g}}\right)$

In standard kinetic experiments, the process rate is considerably low, while the mass and heat transfer inside the bubbles is extremely high due to their small size. So, one can assume the existence of thermodynamics equilibrium inside the bubble in which,

$\frac{d m_{v}}{d m_{g}}=\frac{\mu_{v} P_{v}}{\mu_{g} P_{g}}=\frac{M_{v} P_{v}}{M_{g} P_{g}}$

Taken into consideration that $\mathrm{P}_{\mathrm{v}}+\mathrm{pg}_{\mathrm{g}}=\mathrm{pam}_{\mathrm{m}}$ and $p_{v}=p_{0} e^{(-L / R T)}$, one obtains;

$\frac{d m_{v}}{d m_{g}}=\frac{\mu_{v}}{\mu_{g}} \frac{P_{0} e^{(-L / R T)}}{P_{a m-} P_{0} e^{(-L / R T)}}$

and the gas formation rate can be expressed by $\mathrm{dm} / \mathrm{dt}=$ $k(T) m$ for a first order reaction. So, the heat balance can be expressed as the sum of the heat released at decomposition (gas formation) and absorbed during evaporation in the following form 


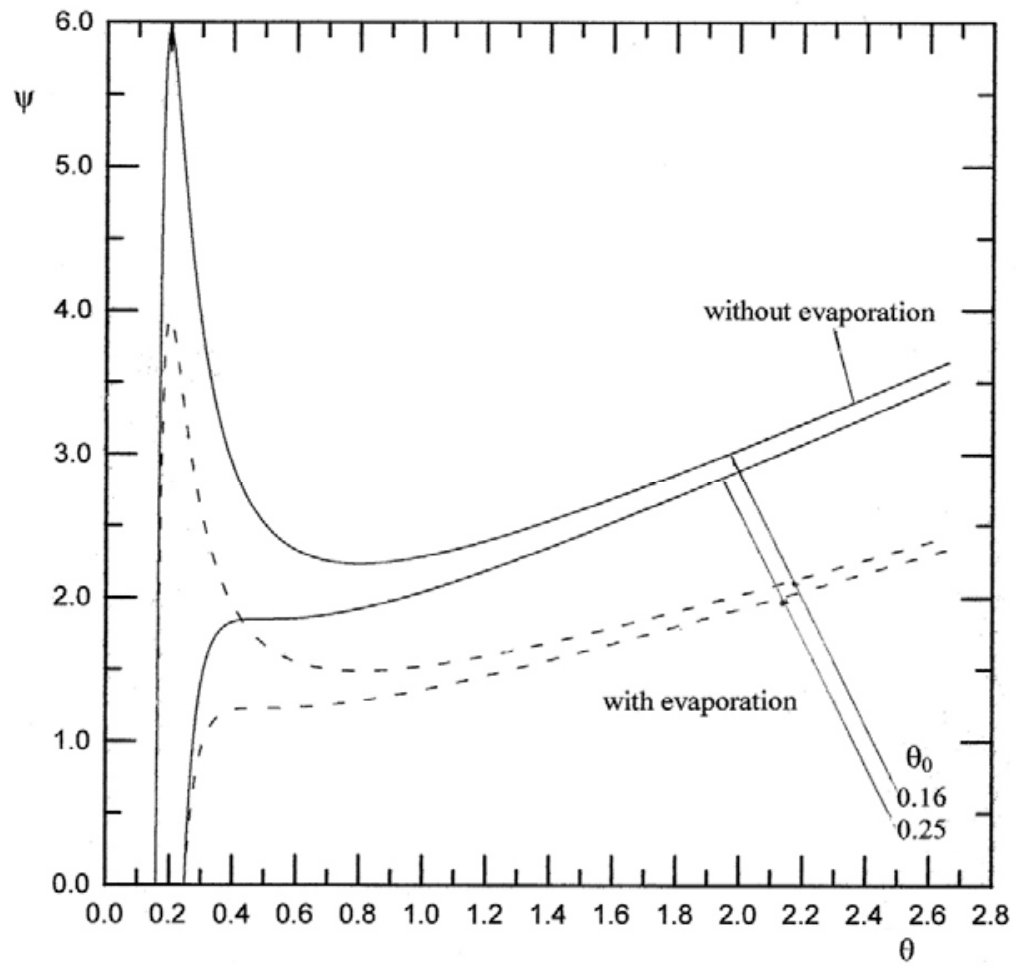

Fig. (1). $\psi$ as a function of $\theta_{\mathrm{m}}$ for nonvolatile liquid and valatile liquid with $(\mathrm{L} a / \mathrm{Qb})=0.5,\left(\mathrm{P}_{\mathrm{am}} / \mathrm{P}_{\mathrm{o}}\right)-0.005,(\mathrm{~L} / \mathrm{E})=0.1$, and $\theta_{0}=0.16$, and 0.25 .

$\frac{d q}{d t}=Q_{g} \frac{d m_{g}}{d t}-L \frac{d m_{v}}{d t}$

Using Eqs. (1-a) - (1-c), one can obtain an expression for the rate of heat evolution:

$\frac{d q}{d t}=Q_{g} \frac{d m_{g}}{d t}\left[1-\frac{L \mu_{v}}{Q_{g} \mu_{g}} \frac{P_{0} e^{(-L / R T)}}{P_{a m-} P_{0} e^{(-L / R T)}}\right]$

If the overall decomposition reaction can be written as: $a$ A (liquid) $\rightarrow$ b B (gas) + c C (liquid or solid), then Eq. (1d) can be transformed identically, yielding

$\frac{d q}{d t}=Q \frac{d m_{l}}{d t}\left[1-\frac{L b}{Q a} \frac{P_{0} e^{(-L / R T)}}{P_{a m-} P_{0} e^{(-L / R T)}}\right]$

Where $\mathrm{dm}_{1} / \mathrm{dt}$ and $\mathrm{Q}$ refer to the decomposing liquid A.

Considering Eq. (1-e), one can write an unsteady heat balance equation for a thermal gradientless process (a uniform instantaneous temperature) of a liquid volatile explosive considering a system characterized as a zero-order reaction using the Arrhenius form of the rate of the reaction in the form [12];

$C \rho \frac{d T}{d t}=Q A_{0} e^{-E / R T}\left[1-\frac{L b}{Q a} \frac{P_{0} e^{-L R T}}{P_{a m}-P_{0} e^{-L R T}}\right]-\frac{h S\left(T-T_{0}\right)}{V}$

The first term on the right-hand side of the above equation referring to the kinetic of heat evolution is quite complex. As temperature grows, its value first increases (not influenced by evaporation) and reaches its maximum value, and then it decreases due to evaporation-related heat absorption. Equation (1-f) can be rewritten in the final form as;

$C \rho \frac{d T}{d t}=Q A_{0} e^{-E / R T}-L A_{0} e^{-E / R T} \frac{b}{a} \frac{P_{0} \mathrm{e}^{-\mathrm{L} / R T}}{P_{a m}-P_{0} \mathrm{e}^{-\mathrm{L} / \mathrm{RT}}}-\frac{h S\left(T-T_{0}\right)}{V}$
So that it can be considered a heat-balance equation for a process with volumetric (the second term in the right-hand side in the equation) and surface (the third part in the righthand side of the equation) heat emission, similar to chain termination in the volume and on the walls in the case of an explosive chain reaction.

Equation (1) can be put in the dimensionless form as;

$\frac{d \theta}{d \tau}=e^{-1 / \theta}-\left(\frac{L b}{Q a}\right) \frac{e^{-(1+(L / E)) / \theta}}{\left(\frac{P_{a m}}{P_{0}}\right)-e^{-L / E \theta}}-\frac{\left(\theta-\theta_{0}\right)}{\psi}$

\section{CRITICAL CONDITIONS FOR DIFFERENT CASES}

Steady-State for a non-adiabatic case: Following lermant and Yip [13] whose demonstrated that the existence of a jump phenomenon in the steady-state solution indicates ignition by examining the variation of the modified Semenov number $(\psi)$ with a temperature $(\theta)$ for a constant $\left(\theta_{\mathrm{a}}\right)$; Considering the steady-state case where

$\mathrm{d} \theta / \mathrm{d} \tau=0$, Eq. (2) gives

$$
\psi=\frac{\left(\theta-\theta_{0}\right)}{e^{-1 / \theta}-\left(\frac{L b}{Q a}\right) \frac{e^{-(1+(L / E)) / \theta}}{\left(\frac{P_{a m}}{P_{0}}\right)-e^{-L / E \theta}}}
$$

Fig. (1) shows $\psi$ as a function of $\theta$ for different values of $\theta_{0}$, for the process without a volumetric evaporation (solid line curves) and with a volumetric evaporation (dashed line curves) with certain values of $\mathrm{L} / \mathrm{E}$ (a dimensionless latent evaporation heat), a dimensionless pressure $\left(\mathrm{P}_{\mathrm{am}} / \mathrm{P}_{0}\right)$, and a dimensionless thermal effect (Lb/Q $a$ ) (ratio between the heat 


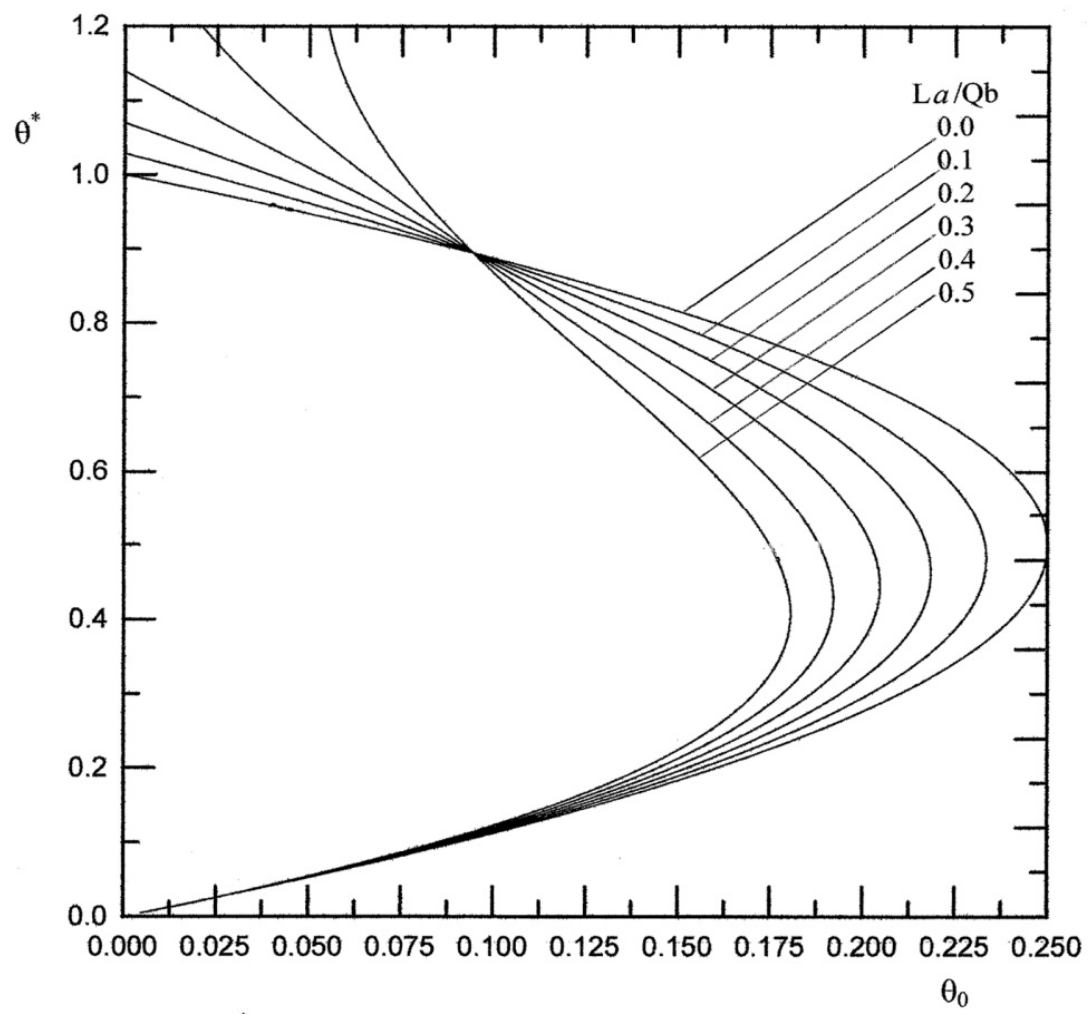

Fig. (2). $\theta^{*}$ as a function of $\theta_{0}$ for $\left(\mathrm{P}_{\mathrm{am}} / \mathrm{P}_{0}\right)=0.005,(\mathrm{~L} / \mathrm{E})=0.1$, and $(\mathrm{L} a / \mathrm{Qb})=0.0,0.1,0.2,0.3,0.4$, and 0.5 .

absorbed during evaporation and heat released by the decomposition of liquid). The figure shows the jump phenomenon and shows that it disappears at $\theta_{0} \geq 0.25\left(\theta_{0 \text { tr }}\right)$ for nonvolatile liquid and a little bit less than for volatile liquid. So, for ignition occurs $\theta_{0}$ should be less than $\theta_{0 \text { tr }}$ and $\psi>\psi^{*}$ (the max value reached where $\theta=\theta_{0}$ at the beginning). To determine the critical condition as a jump phenomenon, we examine the condition for which $\mathrm{d} \psi / \mathrm{d} \theta=0$;

$$
\theta_{0}=\theta^{*}-\frac{1-(L b / Q a) /\left[\left(P_{a m} / P_{0}\right) e^{L / E \theta}-1\right]}{\left(\frac{1}{\theta^{* 2}}\right)-\left(\frac{L b}{Q a}\right) \frac{\left[(1+(L / E)) / \theta^{* 2}\right]\left[\left(\frac{P_{a m}}{P_{0}}\right) e^{L / E \theta}-1\right]+\left(\frac{L}{E \theta^{* 2}}\right) e^{-2 L / E \theta^{*}}}{\left[\left(\frac{P_{a m}}{P_{0}}\right)-e^{-L / E \theta^{*}}\right]^{2}}}
$$

Fig. (2) shows $\theta^{*}$ as a function of $\theta_{0}$ with different values of the dimensionless heat effect ( $\mathrm{Lb} / \mathrm{Q} a)$. The lower branch of the curves shows ignition temperature and the upper branch of the curves shows extinction temperature. The two branches of the curve meet in the transition point at which ignition tends to disappear. The graphs show as (Lb/Q $a$ ) increases the ignition region (area under the curves) decreases. This means that higher values of $(\mathrm{Lb} / \mathrm{Q} a)$ produce high ignition temperature values at a certain value of $\theta_{0}$ and lower values for extinction temperature. It can also be seen that up to $\theta_{0}=0.1$, the critical explosion temperature with and without evaporation are almost coincided, while the critical extinction temperature (cooling) for the evaporating material is higher than that of the non-evaporating substance. For $\theta_{0}$ $>0.1$, the limiting explosion temperature exceeds the temperature characteristics for the process without evaporation, (when the liquid vapor pressure is much lower than the ambient pressure), while the opposite is considered in the case of an extinction process. So the transitional values (at which the criticality disappears), for the volatile liquid are lower than that of the nonvolatile liquid. Fig. (3) shows $\theta^{*}$ as a function of $\theta_{0}$ with different values of $(\mathrm{L} / \mathrm{E})$. As shown in the figure, as the value of $(\mathrm{L} / \mathrm{E})$ increases, the ignition temperature value decreases. This means that low activation energy of the liquid or high latent heat of vaporization of the liquid lead to an explosion of the material at low temperatures. So, the safety of handling or storage of the volatile materials is more difficult than the non-volatile ones.

For heat released without the volumetric evaporation (a non-volatile liquid explosive), Eq. 4 is reduced to the form of the classical Semenov problem of homogenous gas mixture (or well stirred reactor) as:

$\theta^{*^{2}}-\theta^{*}+\theta_{0}=0$ And $\psi^{*}=\left(\theta^{*}-\theta_{0}\right) e^{1 / \theta^{*}}=\theta^{*^{2}} e^{1 / \theta^{*}}$

This means that the part of the volumetric evaporation term in the Eq. (2) is zero. This gives

$$
\left(\frac{L b}{Q a}\right) \frac{e^{-(1+(L / E)) / \theta}}{\left(\frac{P_{a m}}{P_{0}}\right)-e^{-L / E \theta}}=0
$$

So, when the liquid vapor pressure is much lower than the ambient pressure and at a low temperature, the heat released due to chemical reaction does not show any change. The explosion temperature by evaporation exceeds the explosion temperature without evaporation. One can see that for the same conditions, the critical $\psi^{*}$ (high heat transfer loss (h) or high surface/ volume ratio (S/V)) corresponding to the explosion initiation limit for a volatile liquid is lower than that for a non-volatile liquid (characterized by the absence of volumetric heat absorption). 


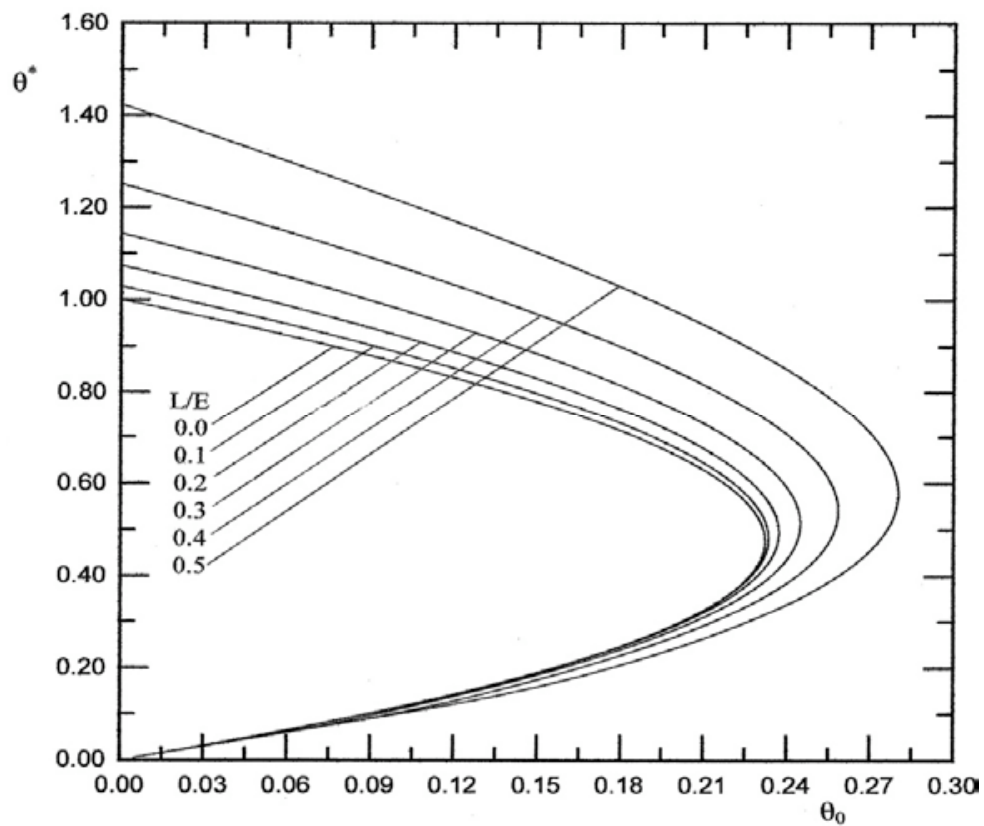

Fig. (3). $\theta^{*}$ as a function of $\theta 0$ for $(\mathrm{L} a / \mathrm{Qb})=0.1,\left(\mathrm{P}_{\mathrm{am}} / \mathrm{P}_{0}\right)=0.005$, and $(\mathrm{L} / \mathrm{E})-0.0,0.1,0.2,0.3,0.4$, and 0.5 .

Steady-state of an adiabatic system case: The upper limit of temperature of liquid is $\theta_{\text {ad }}$, which corresponds to the adiabatic process. Setting $d \theta / d \tau=0$ and $\psi=\infty$, Equation (2) produces

$e^{-1 / \theta_{a d}}-\left(\frac{L b}{Q a}\right) \frac{e^{-(1+(L / E)) / \theta_{a d}}}{\left(\frac{P_{a m}}{P_{0}}\right)-e^{-L / E \theta_{a d}}}=0$

Rearranging Eq. (7), gives the adiabatic temperature $\theta_{\mathrm{ad}}$ in the form

$\theta_{a d}=\frac{L}{E} \frac{1}{\ln \left[\left(\frac{P_{0}}{P_{a m}}\right)\left\{\left(\frac{L b}{Q a}\right)+1\right\}\right]}$

We introduce the theoretical liquid boiling temperature, $T_{b}$, determining from $P_{a m}=P_{0} \mathrm{e}^{-\mathrm{L} / \mathrm{R} \mathrm{T}_{\mathrm{b}}}$ or in a dimensionless form as $\left(\frac{P_{a m}}{P_{0}}\right)=e^{-L / E \theta_{b}}$ and substituting this term into Eq. (8); gives

$\theta_{a d}=\frac{1}{\frac{1}{\theta_{b}}+\left(\frac{E}{L}\right) \ln \left[\left(\frac{L b}{Q a}\right)+1\right]}$

For approximation since $\ln \left[\left(\frac{L b}{Q a}\right)+1\right] \ll<1$

$\therefore \quad \theta_{a d}=\frac{1}{\theta_{b}}-\left(\frac{E}{L}\right) \ln \left[\left(\frac{L b}{Q a}\right)+1\right]$

It can be seen that $\theta_{a d}$ increases as $\mathrm{P}_{\mathrm{am}}$ increases and always remain less than the boiling point.

Unsteady-state of the adiabatic system $(d \theta / d \tau \neq 0$ and $\psi=\infty$ ) case : In this case, Eq. (2) can be set in the form

$$
\frac{d \theta}{d \tau}=e^{-1 / \theta}-\left(\frac{L b}{Q a}\right) \frac{e^{-(1+(L / E)) / \theta}}{\left(\frac{P_{a m}}{P_{0}}\right)-e^{-L / E \theta}}
$$

The critical condition is defined as the point at which an inflection point occurs in the temperature - time trajectory before a maximum is reached $[14,15])$. Differentiating Eq. (2) with respect to time and equating the result to zero; yielding the following

$$
\psi^{*}=\frac{\left(\theta_{a d}-\theta_{0}\right)}{e^{-1 / \theta_{a d}}-\left(\frac{L b}{Q a}\right) \frac{e^{-(1+(L / E)) / \theta_{a d}}}{\left(\frac{P_{a m}}{P_{0}}\right)-e^{-L / E \theta_{a d}}}}
$$

And

$$
\theta_{a d}=\frac{(L / E)}{\ln \left\{\frac{1}{\left(P_{a m} / P_{0}\right)}\left[1-\frac{1}{2}\left(\frac{-L b}{Q a}\right)\left(\frac{L+E}{E}\right) \pm \frac{1}{2} \sqrt{\left(\frac{l b}{Q a}\right)^{2}\left(\frac{L+E}{E}\right)^{2}-\frac{4 L}{E}\left(\frac{L b}{Q a}\right)}\right]\right\}}
$$

Fig. (4) shows $\theta_{a d}$ as a function of $(L \mathrm{~b} / \mathrm{Q} a)$ for different conditions. This figure shows that the thermal effect depends on temperature and pressure (for a constant reaction mechanism). It can be seen that at certain ( $L \mathrm{~b} / \mathrm{Q} a)$, as ambient pressure increases the adiabatic (critical) temperature in adiabatic system increases.

For steady-state and inflection point to exist in the adiabatic system, that is, for the critical point Eq. (11) produces;

$\left(\frac{L b}{Q a}\right) \frac{e^{-(1+(L / E)) / \theta_{a d}}}{\left(\frac{P_{a m}}{P_{0}}\right)-e^{-L / E \theta_{a d}}}=1$

This equation gives 


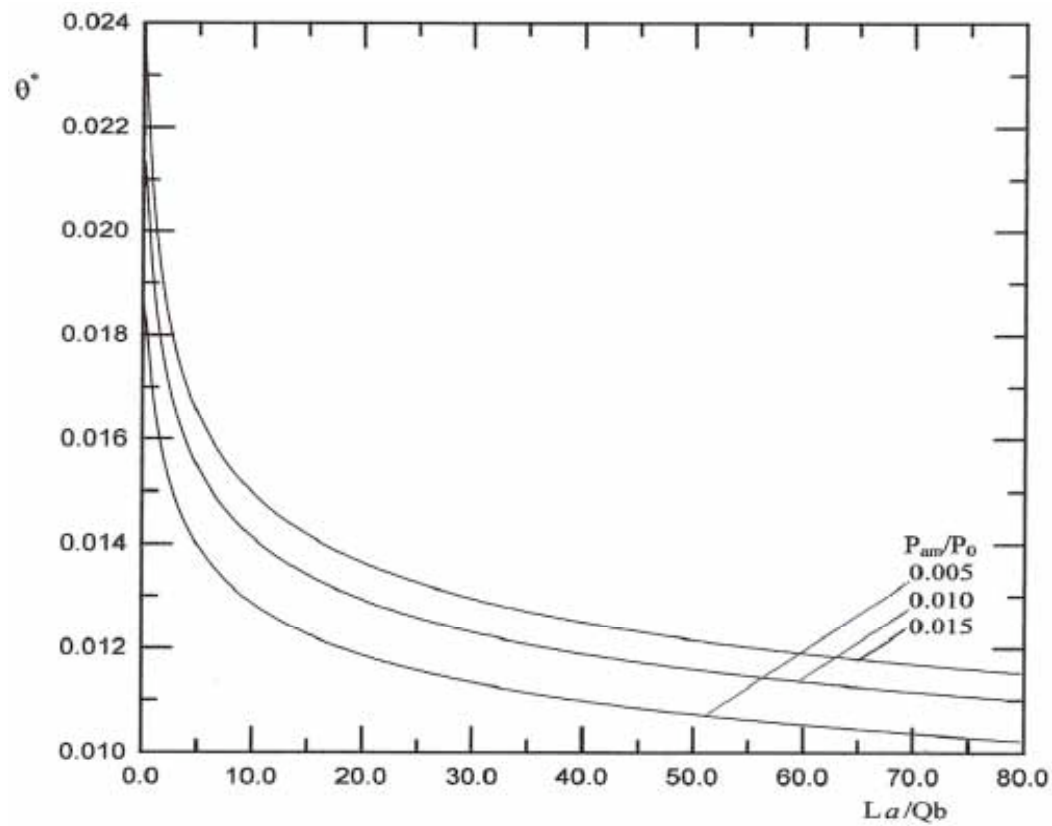

Fig. (4). $\theta^{*}$ as a function of $(\mathrm{L} a / \mathrm{Qb})$ for $(\mathrm{L} / \mathrm{E})=0.1$, and $\left(\mathrm{P}_{\mathrm{am}} / \mathrm{P}_{0}\right)=0.005,0.01$ and 0.015 (Adiabatic case).

$\theta_{a d}=1 / \ln \left[\frac{(L b / Q a)}{\left(p_{a m} / p_{0}\right)}\right]$

One can see that if $\mathrm{P}_{a m}$ value decreases, $\theta_{\mathrm{ad}}$ value decreases. Also, at a certain value of $\mathrm{P}_{a m}$, as $(L \mathrm{~b} / \mathrm{Q} a)$ value increases, $\theta_{\mathrm{ad}}$ value decreases.

Unsteady-state of the non-adiabatic system $((d \theta / d \tau \neq$ 0 and $\psi \neq \infty$ ) case: To investigate the inflection point in the temperature - time trajectory, Eq. (2) is differentiated with respect to time, which gives

$\frac{d^{2} \theta}{d \tau^{2}}=\left[e^{-1 / \theta}-\left(\frac{l b}{Q a}\right) \frac{e^{-(1+(L / E)) / \theta}}{\left(\frac{P_{a m}}{P_{0}}\right)-e^{-L / E \theta}}-\frac{\left(\theta-\theta_{0}\right)}{\psi}\right] x$

$\left[\frac{e^{-1 / \theta}}{\theta^{2}}-\left(\frac{L b}{Q a}\right) \frac{e^{-(1+(L / E)) / \theta}\left((L+E) / E \theta^{2}\right)\left\{\left(\frac{P_{a m}}{P_{0}}\right)-e^{-L / E \theta}\right\}+\frac{L}{E \theta^{2}} e^{-(1+(2 / / E)) / \theta}}{\left\{\left(\frac{P_{a m}}{P_{0}}\right)-e^{-L / E \theta}\right\}^{2}}\right]$

For both an inflection point and the steady - state solution to exist, that is, for the critical point, Eq. (15) is equated to zero where both parts of that equation yields

$$
\psi^{*}=\frac{\left(\theta^{*}-\theta_{0}\right)}{e^{-1 / \theta^{*}}-\left(\frac{L b}{Q a}\right) \frac{e^{-(1+(L / E)) / \theta^{*}}}{\left(\frac{P_{a m}}{P_{0}}\right)-e^{-L / E \theta^{*}}}}=
$$

$\frac{\theta^{*^{2}} e^{1 / \theta^{*}}}{1-\left(\frac{L b}{Q a}\right) \frac{(1+(L / E)) e^{-L / E \theta^{*}}\left[\left(\frac{P_{a m}}{P_{0}}\right)-e^{-L / E \theta^{*}}\right]+\frac{L}{E} e^{-2 L / E \theta^{*}}}{\left[\left(\frac{P_{a m}}{P_{0}}\right)-e^{-L / E \theta^{*}}\right]^{2}}}$

So at $\theta_{0}$ the pressure of the original liquid vapor is significantly lower than the ambient pressure, then the explosion limit maximum warm up $\left(\theta^{*}-\theta_{0}\right)$ can be estimated from Equation (16) in the form

$$
\theta^{*}-\theta_{0}=\frac{\theta^{*^{2}}\left[1-\left(\frac{L b}{Q a}\right) \frac{e^{-L / E \theta^{*}}}{\left(\frac{p_{a m}}{p_{0}}-e^{-L / E \theta^{*}}\right)}\right]}{1-\left(\frac{L b}{Q a}\right) \frac{(1+(L / E))\left(\frac{p_{a m}}{p_{0}}-e^{-L / E \theta^{*}}\right)+\left(\frac{L}{E}\right) e^{-L / E \theta^{*}}}{e^{L / E \theta^{*}}\left(\frac{P_{a m}}{p_{0}}-e^{-L / E \theta^{*}}\right)^{2}}}
$$

This expression differs from the Semenov critical condition by the second term in the square brackets in the nominator and dominator on the right-hand side. According to this expression, the critical conditions for a volatile explosive can be attained at lower heat removal rates due to partial heat removal by the volumetric evaporation. On the other hand, if the liquid vapor pressure is much lower than the ambient pressure or the thermal effect of the reaction is much higher than the phase transition heat $[(\mathrm{Lb} / \mathrm{Q} a)<<1.0]$, that is the critical condition obtained becomes identical to the Semenov one $\left[\theta^{* 2}-\theta^{*}+\theta_{0}=0\right]$. Since for $\exp (\mathrm{L} / \mathrm{E})(L b / Q a)(1+\mathrm{L} / \mathrm{E}) \sim 1.0$ for many practically interesting systems, the classical theory, which does not take volumetric evaporation into account, can be used to estimate the critical parameters for the thermal explosion provided $\mathrm{P}_{\mathrm{sv}}\left(\mathrm{T}_{0}\right)<<\mathrm{P}_{a m}$. Figs. (5 and 6) show $\theta^{*}$ as a function of $\theta_{0}$ at different values of thermal effect ( $\left.\mathrm{Lb} / \mathrm{Q} a\right)$, and latent evaporation heat $(\mathrm{L} / \mathrm{E})$. All curves are similar at the behavior. All figures show that as $\theta_{0}$ increases the ignition region becomes wider. Also we can conclude from the figures that for $\theta_{0}<0.06$, the ignition temperatures (lower branch of the curves) almost have the same values. Each curve shows a transition point $\left(\theta^{*}{ }_{\text {tr }}\right.$ and $\left.\theta_{0_{t}}\right)$ at which the criticality disappears. Table 1 shows the different values of transitional 


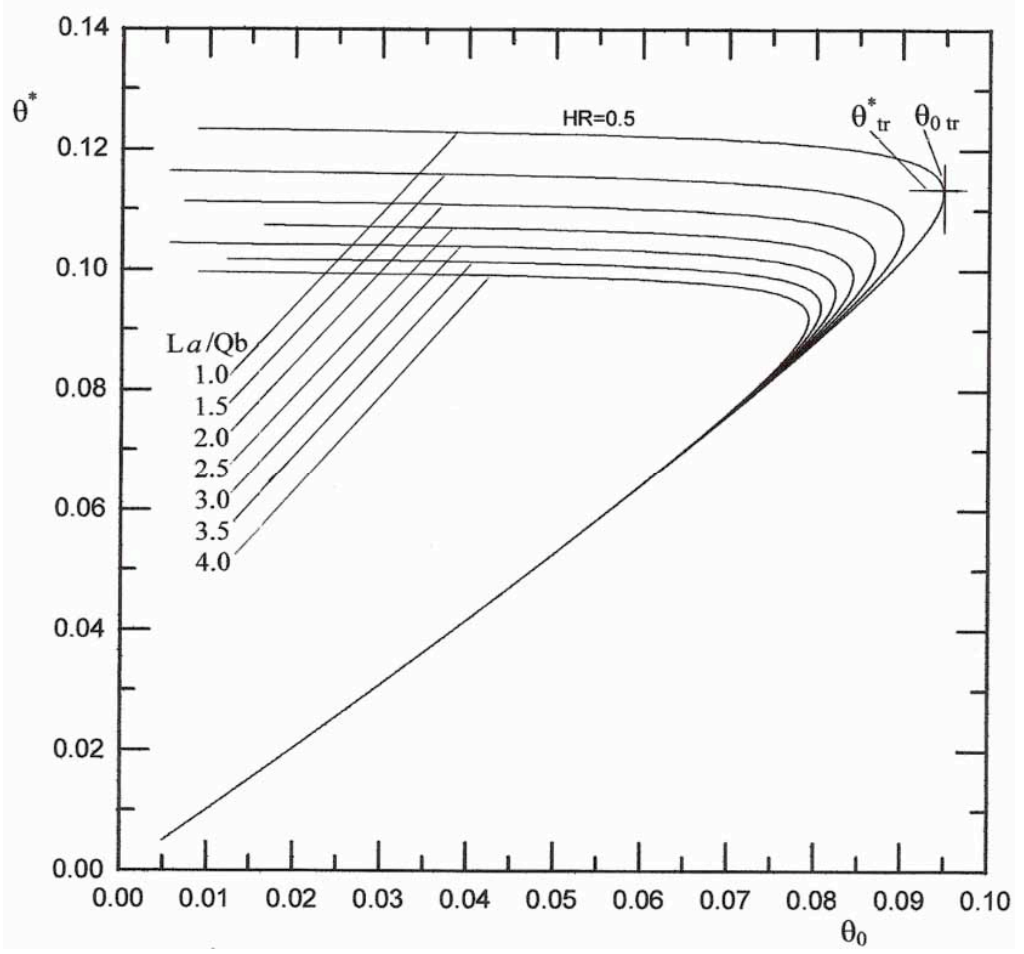

Fig. (5). $\theta^{*}$ as a function of $\theta_{0}$ for $(\mathrm{Pam} / \mathrm{P} 0)=0.005,0.01$ and $0.015(\mathrm{~L} / \mathrm{E})=0.5$, and $(\mathrm{L} a / \mathrm{Qb})=1.0,1.5,2.0,2.5,3.0,3.5$, and 4.0.

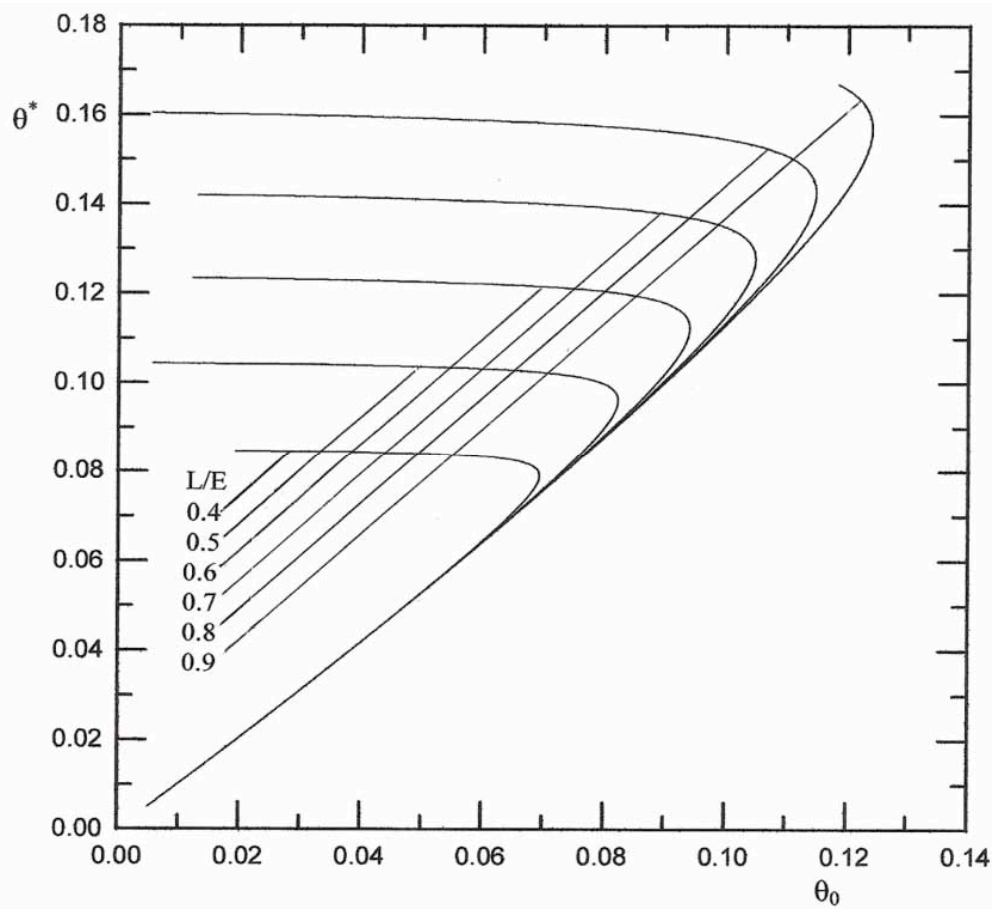

Fig. (6). $\theta^{*}$ as a function of $\theta_{0}$ for $\left(\mathrm{P}_{\mathrm{am}} / \mathrm{P}_{0}\right)=0.005,(\mathrm{~L} a / \mathrm{Qb})-3.0$, and $(\mathrm{L} / \mathrm{E})$ 0.4, 0.5, 0.6, 0.7, 0.8, and 0.9.

Table 1. Transitional values for Different $(\mathrm{Lb} / \mathrm{Q} a),(\mathrm{L} / \mathrm{E})$, and $\left(\mathrm{P}_{\mathrm{am}} / \mathrm{P}_{\mathbf{0}}\right)$

\begin{tabular}{|c|c|c|c|c|c|c|}
\hline $\mathbf{L b} / \mathbf{Q} \boldsymbol{a}$ & $\mathbf{1 . 0}$ & $\mathbf{1 . 5}$ & $\mathbf{2 . 0}$ & $\mathbf{2 . 5}$ & $\mathbf{3 . 0}$ & $\mathbf{3 . 5}$ \\
\hline \hline$\theta_{\text {tr }}$ & 0.0947 & 0.09008 & 0.08681 & 0.08431 & 0.08229 & 0.08062 \\
\hline$\theta_{\mathrm{tr}}^{*}$ & 0.1129 & 0.1065 & 0.1022 & 0.0988 & 0.0961 & 0.0939 \\
\hline $\mathrm{L} / \mathrm{E}$ & 0.4 & 0.5 & 0.6 & 0.7 & 0.8 & 0.1148 \\
\hline$\theta_{\text {tr }}$ & 0.06937 & 0.08229 & 0.09407 & 0.1049 & 0.1240 \\
\hline
\end{tabular}


Table 1. contd...

\begin{tabular}{|c|c|c|c|c|c|c|}
\hline $\mathbf{L b} / \mathbf{Q} \boldsymbol{a}$ & $\mathbf{1 . 0}$ & $\mathbf{1 . 5}$ & $\mathbf{2 . 0}$ & $\mathbf{2 . 5}$ & $\mathbf{3 . 0}$ & $\mathbf{3 . 5}$ \\
\hline \hline$\theta_{\text {tr }}^{*}$ & 0.0791 & 0.0961 & 0.1123 & 0.1278 & 0.1427 & 0.1570 \\
\hline $\mathrm{P}_{\mathrm{am}} / \mathrm{P}_{0}$ & 0.05 & 0.10 & 0.15 & 0.20 & 0.25 & 0.30 \\
\hline$\theta_{\text {tr }}$ & 0.0637 & 0.07861 & 0.08519 & 0.09054 & 0.09515 & 0.09925 \\
\hline$\theta_{\text {tr }}^{*}$ & 0.0791 & 0.0914 & 0.1007 & 0.1083 & 0.1152 & 0.1214 \\
\hline
\end{tabular}

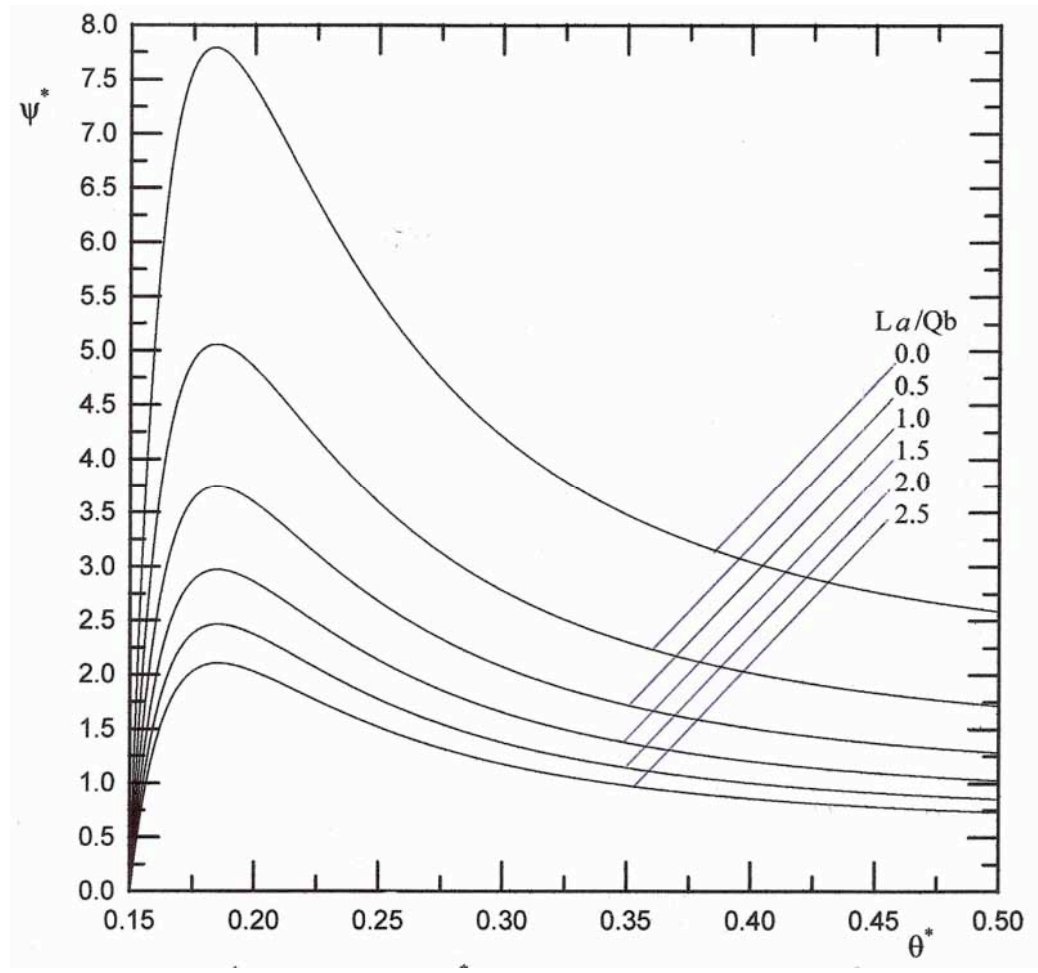

Fig. (7). $\psi^{*}$ as a function of $\theta^{*}$ for $\left(\mathrm{P}_{\mathrm{am}} / \mathrm{P}_{\mathrm{o}}\right)-0.03,(\mathrm{~L} / \mathrm{E})=0.2$, and $(\mathrm{L} a / \mathrm{Qb})=0.0,0.5,1.0,1.5,2.0$, and 2.5 .

points. Fig. (7) shows $\psi^{*}$ as function of $\theta^{*}$. It can be seen that the volatile liquid shows higher values of $\psi$ than the nonvolatile liquid due to the absence of the volumetric heat absorption. One can also see that increasing the value of $(\mathrm{Lb} / \mathrm{Q} a)$, results in an increase of the critical ignition temperature.

The relation between the modified Semenov numbers in both cases of nonvolatile explosive and volatile explosive can be obtained by dividing Eq. (15) with Eq. (5), which yields

$$
\frac{\psi_{v}^{*}}{\psi^{*}}=1-\frac{(L b / Q a)}{\left(\frac{P_{a m}}{P_{0}}\right)-e^{-L / E \theta^{*}}}
$$

If $(\mathrm{Lb} / \mathrm{Q} a)=0$ (no evaporation), then $\psi_{\mathrm{v}}{ }^{*}=\psi^{*}$. For $(L b / Q a)<<\left(\frac{p_{a m}}{p_{0}}-e^{-L / E \theta^{*}}\right), \psi_{v}^{*} \rightarrow \psi^{*}$.

If we use the Frank-Kamenetskii approximation to the rate law where the temperature excess can be defined as $\varphi=\frac{T-T_{0}}{R T_{0}^{2}}=\frac{\theta-\theta_{0}}{\theta_{0}^{2}}$, and $e^{-1 / \theta}=e^{\varphi} \cdot e^{-1 / \theta_{0}}, \quad \psi^{\prime}=\psi / \theta_{0}^{2} e^{1 / \theta_{0}}$, and $\tau^{\prime}=\tau / \theta_{0}^{2} e^{1 / \theta_{0}}$ then, Eq. (2) can be rewritten in the following form as

$\frac{d \varphi}{d \tau^{\prime}}=e^{\varphi}-\left(\frac{L b}{Q a}\right) \frac{e^{(1+(L / E)) \varphi}}{\left(\frac{P_{a m}}{P_{0}}\right) e^{L / E \theta_{0}}-e^{L \varphi / E}}-\frac{\varphi}{\psi^{\prime}}$

For the steady-state solution $\left(d \varphi / d \tau^{\prime}=0\right)$, Eq. (19) gives

$$
\psi^{\prime}=\frac{\varphi e^{-\varphi}}{1-\left(\frac{L b}{Q a}\right) \frac{e^{L \varphi / E}}{\left(\frac{P_{a m}}{P_{0}}\right) e^{L / E \theta_{0}}-e^{L \varphi / E}}}
$$

The critical conditions can be obtained by differentiating Eq. (20) with respect to $\phi$ and equating the result to zero, yielding

$$
\begin{aligned}
& \left(1-\varphi^{*}\right) e^{-2 L \varphi^{*} / E_{e}}{ }^{2 L / E \theta_{0}}\left(\frac{p_{a m}}{p_{0}}\right)^{2}+\left[\frac{L \varphi^{*}}{E}\left(\frac{L b}{Q a}\right)-\left(1-\varphi^{*}\right)\left(\frac{L b}{Q a}\right)-2\left(1-\varphi^{*}\right)\right] x \\
& e^{-L \varphi^{*} / E_{e}}{ }^{L / E \theta_{0}}\left(\frac{p_{a m}}{p_{0}}\right)+\left(1+\left(\frac{L b}{Q a}\right)\right)\left(1-\varphi^{*}\right)=0
\end{aligned}
$$




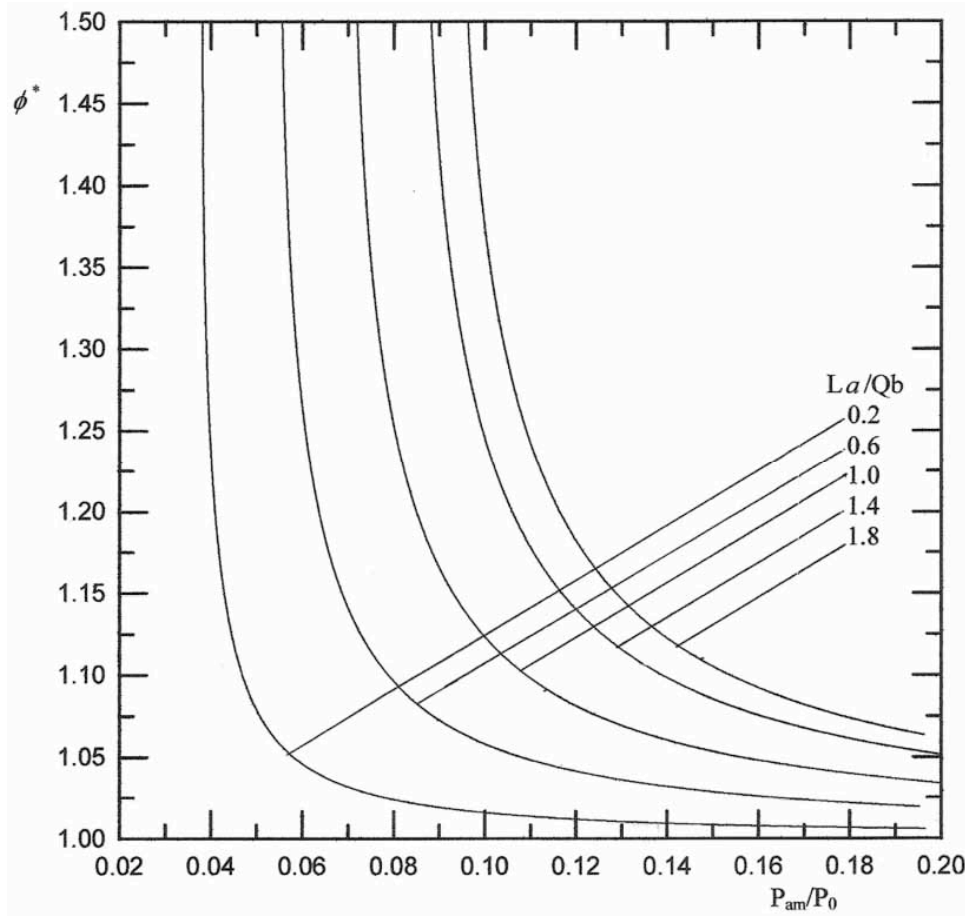

Fig. (8). $\phi^{*}$ as a function of $\left(\mathrm{P}_{\mathrm{am}} / \mathrm{P}_{0}\right)$ for $(\mathrm{L} / \mathrm{E})=0.5, \theta_{0}=0.05$, and $(\mathrm{L} a / \mathrm{Qb})=0.2,0.6,1.0,1.4$, and 1.8 .

This quadratic can be solved for different values of $(\mathrm{Lb} / \mathrm{Q} a),(\mathrm{L} / \mathrm{E})$, and $\left(\mathrm{P}_{\mathrm{am}} / \mathrm{P}_{0}\right)$. Fig. (8) shows $\phi^{*}$ as a function of $\left(\mathrm{P}_{\mathrm{am}} / \mathrm{P}_{0}\right)$ for different values of $(\mathrm{Lb} / \mathrm{Q} a)$. It can be seen that at certain value of $\left(\mathrm{P}_{\mathrm{am}} / \mathrm{P}_{0}\right)$, as $(\mathrm{Lb} / \mathrm{Q} a)$ increases the value of $\phi^{*}$ increases. As $(\mathrm{Lb} / \mathrm{Q} a)$ increases, the ignition region (area under the curve) becomes larger.

One can see that for a nonvolatile liquid $(L b / Q a)=0$, Eqns. (21) and (20); give

$\varphi^{*}=1.0$ and $\psi^{*}=\varphi^{*} e^{-\varphi^{*}}$

Which represents the Frank-Kamenetskii solution of the classical problem where $\psi^{*}=\delta_{F . K}^{*}$ (where $\delta_{F . K}$ is the FrankKamenetskii number).

In the adiabatic case of the steady-state solution $\left(d \varphi / d \tau^{\prime}=0\right.$ and $\left.\psi^{\prime}=\infty\right)$, Eq. (19) produces

$\varphi_{a d}=\theta_{0}+\left(\frac{E}{L}\right) \ln \left[\frac{\left(P_{a m} / p_{0}\right)}{1+(L b / Q a)}\right]$

If we consider the boiling temperature of the liquid, where $\left(p_{a m} / p_{0}\right)=e^{-L / E \theta_{b}}=e^{\varphi_{b L / E}} \cdot e^{-L / E \theta_{0}}$, then Eq. (23) gives;

$\varphi_{a d}=\varphi_{b}+\left(\frac{E}{L}\right) \ln \left[1+\left(\frac{L b}{Q a}\right)\right]^{-1}$

where $\varphi_{b}>\varphi_{a d}$.

In the adiabatic case of the unsteady state $\operatorname{system}\left(d \varphi / d \tau^{\prime} \neq 0\right.$ and $\left.\psi^{\prime}=\infty\right)$, Eq. (19) becomes

$\frac{d \varphi}{d \tau}=e^{\varphi}-\left(\frac{L b}{Q a}\right) \frac{e^{(1+(L / E)) \varphi}}{\left(\frac{P_{a m}}{P_{0}}\right) e^{L / E \theta_{0}}-e^{L \varphi / E}}$
The critical conditions can be obtained by differentiating Eq. (25) with respect to time and equating the result to zero (inflection point), yielding

$$
\begin{aligned}
& {\left[1+\left(\frac{L b}{Q a}\right)+2\left(\frac{L}{E}\right)\left(\frac{L b}{Q a}\right)\right] e^{-2 L I E \theta_{0}} \cdot e^{2 L \varphi^{2} / E}+\left[2+\left(\frac{L b}{Q a}\right)+\left(\frac{L}{E}\right)\left(\frac{L b}{Q a}\right)\right]} \\
& \left(\frac{p_{a m}}{p_{0}}\right) e^{-L L \theta_{0}} \cdot e^{L \varphi^{*} I E}\left(\frac{p_{a m}}{p_{0}}\right)^{2}=0
\end{aligned}
$$

The solution of this quadratic equation gives the critical temperature $\varphi^{*}$ as a function of different values of the $(\mathrm{Lb} / \mathrm{Q} a),(\mathrm{L} / \mathrm{E})$, and $\left(\mathrm{P}_{\mathrm{am}} / \mathrm{P}_{0}\right)$.

For the non-adiabatic case of the unsteady - state solution, the critical conditions can be obtained by differentiating Eq. (19) with respect to time and equating the result to zero (inflection point), yielding

$$
\psi^{*}=\frac{\varphi^{*} e^{-\varphi^{*}}}{1-\left(\frac{L b}{Q a}\right) \frac{e^{L \varphi^{*} / E}}{\left(\frac{P_{a m}}{P_{0}}\right) e^{L / E \theta_{0}}-e^{L \varphi^{*} / E}}}
$$

and

$$
\psi^{\prime \prime}=\frac{1}{1-\left(\frac{L b}{Q a}\right) \frac{\left(1+\frac{L}{E}\right) e^{L \varphi^{\prime} / E} \cdot e^{-L E E \theta_{0}}\left[\left(\frac{p_{a m}}{p_{0}}\right)-e^{L \varphi^{\prime} / E} \cdot e^{-L E E_{0}}\right]-\left(\frac{L}{E}\right) e^{2 L \phi^{\prime} / E} \cdot e^{-2 L I E \theta_{0}}}{\left[\left(\frac{p_{a m}}{p_{0}}\right)-e^{L \varphi^{\prime} / E} \cdot e^{-L L E \theta_{0}}\right]^{2}}}
$$

For both inflection point and a steady-state solution to exist, that is, for the critical point Eqs. (27-a) and (27-b) gives the critical temperature a $\phi^{*}$ as a function of $(\mathrm{Lb} / \mathrm{Q} a)$, $(\mathrm{L} / \mathrm{E}),\left(\mathrm{P}_{\mathrm{am}} / \mathrm{P}_{0}\right)$, and $\theta_{0}$. It can be seen that for the non-volatile system, $(L b / Q a)=0$ the Frank-Kamenetskii solution can be obtained in the same form as in Eq. (22). 


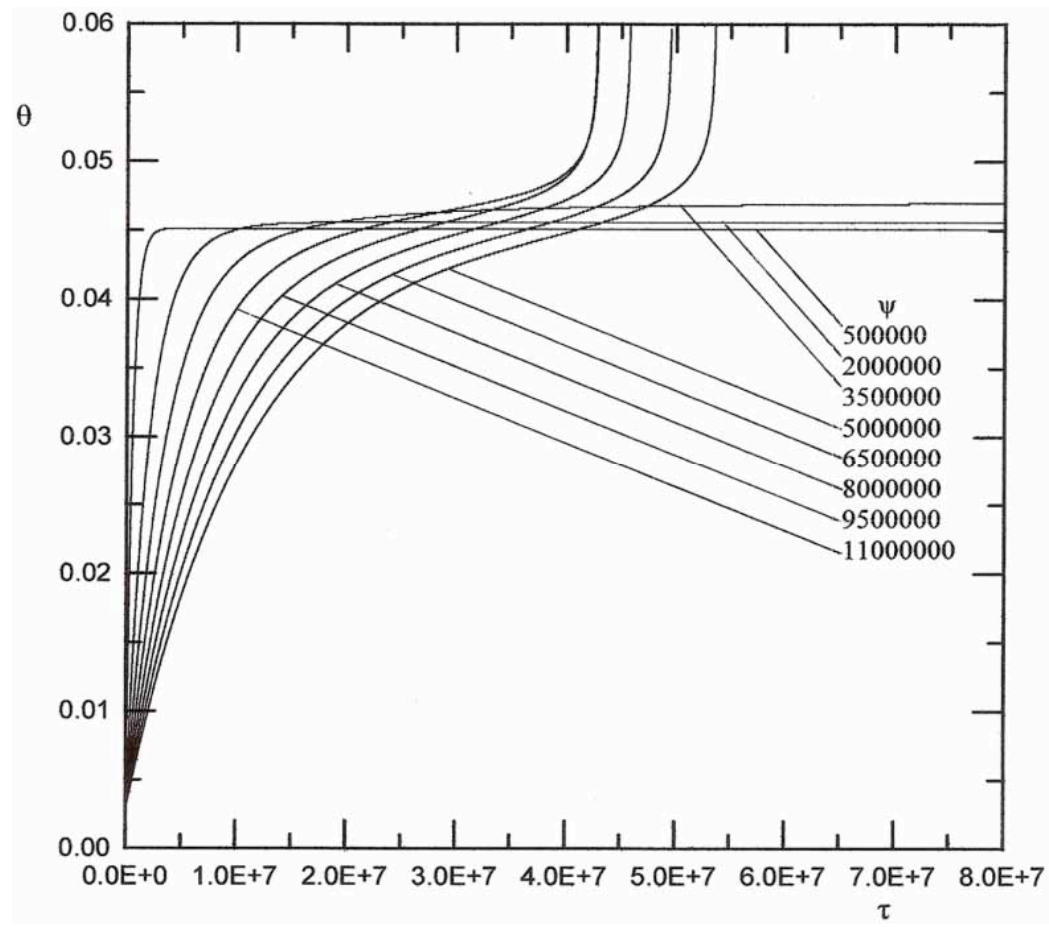

Fig. (9). $\theta-\tau$ trajectories for $\left(\mathrm{P}_{\mathrm{am}} / \mathrm{P}_{0}\right)=0.05,(\mathrm{~L} / \mathrm{E})=0.5, \theta_{0}=0.045,(\mathrm{~L} a / \mathrm{Qb})=5000$, and $\psi=500000,2000000,3500000,5000000$, $6500000,8000000,9500000$, and 11000000 .

The relationship between the critical parameters for both volatile and non-volatile materials can be put in the form

$$
\frac{\psi_{v}^{*}}{\psi^{*}}=\frac{1}{1-\left(\frac{L b}{Q a}\right) \frac{1}{\left[\left(\frac{P_{a m}}{P_{0}}\right) e^{-L \varphi^{*} / E} e^{L / E \theta_{0}}-1\right]}}
$$

$$
\text { If }(L b / Q a)=0 \text {, then } \psi_{\mathrm{v}}^{*}=\psi^{*} \text {. For }(L b / Q a)<<
$$
$\left(\frac{p_{a m}}{p_{0}}\right) e^{-L \varphi^{*} / E} e^{L / E \theta_{0}}-1, \psi_{v}^{*}>\psi^{*}$ and vice versa.

\section{NUMERICAL SOLUTION}

Equation (2) can be integrated directly by using fourth order Runga-Kutta method with high precision of incremental time. This direct integration produces a whole family of curves for different initial conditions and different parameters. Fig. (9) shows the temperature -time histories for different values of $\psi$. It can be seen that for self-heating (subcritical) curves the temperature increases as the time increases till a certain time, then the temperature remains constant (maximum temperature). This means that the temperature is not enough for sustained ignition of the material. For self-ignition (supercritical) curves the temperature increases with time till a certain time, then thermally runaway occurs and ignition happened. One can notice that these supercritical curves show an inflection point. At this inflection point (ignition point) the ignition temperature and ignition time can be obtained. The boundary between non-ignition and ignition curves is called the critical boundary at which the critical condition can be obtained as shown before in the analytical part. Fig. (10) shows the temperature -time histories for different values of $(\mathrm{Lb} / \mathrm{Q} a)$.
In this case, one can see that in the thermal runaway curve the temperature jumps suddenly to high values, then remains constant. The effect of the initial temperature $\theta_{0}$ on the behavior of the function is shown in Fig. (11). One can see that if the value of the initial temperature is not enough to lead ignition, the temperature increases till the maximum value then remains constant. As the initial temperature values increases the behavior of the curves show thermal runaway and ignition occurs and the critical boundary between no-ignition and ignition cases is shown in the figure.

\section{CONCLUSIONS}

From the previous results and discussion, the following conclusions can be derived as:

1. The thermal explosion theory for the non-volatile explosive can be applied to the volatile explosives producing important results.

2. Analytical treatments for the problem for both steady and unsteady state cases are offered. It was shown that the limiting explosion temperature of the evaporating liquid is higher than that of the nonevaporating liquid. Also the critical extinction temperature (cooling) for evaporating liquid is lower than that of the non-evaporating liquid. It is shown also that, if all other conditions are the same, the critical heat transmission $\left(\psi^{*}\right)$, corresponding to the explosion initiation limit for a volatile liquid is lower than that for a nonvolatile liquid (characterized by the absence of volumetric heat absorption).

3. The analytical solution produces different mathematical expressions for the critical and transition conditions. 


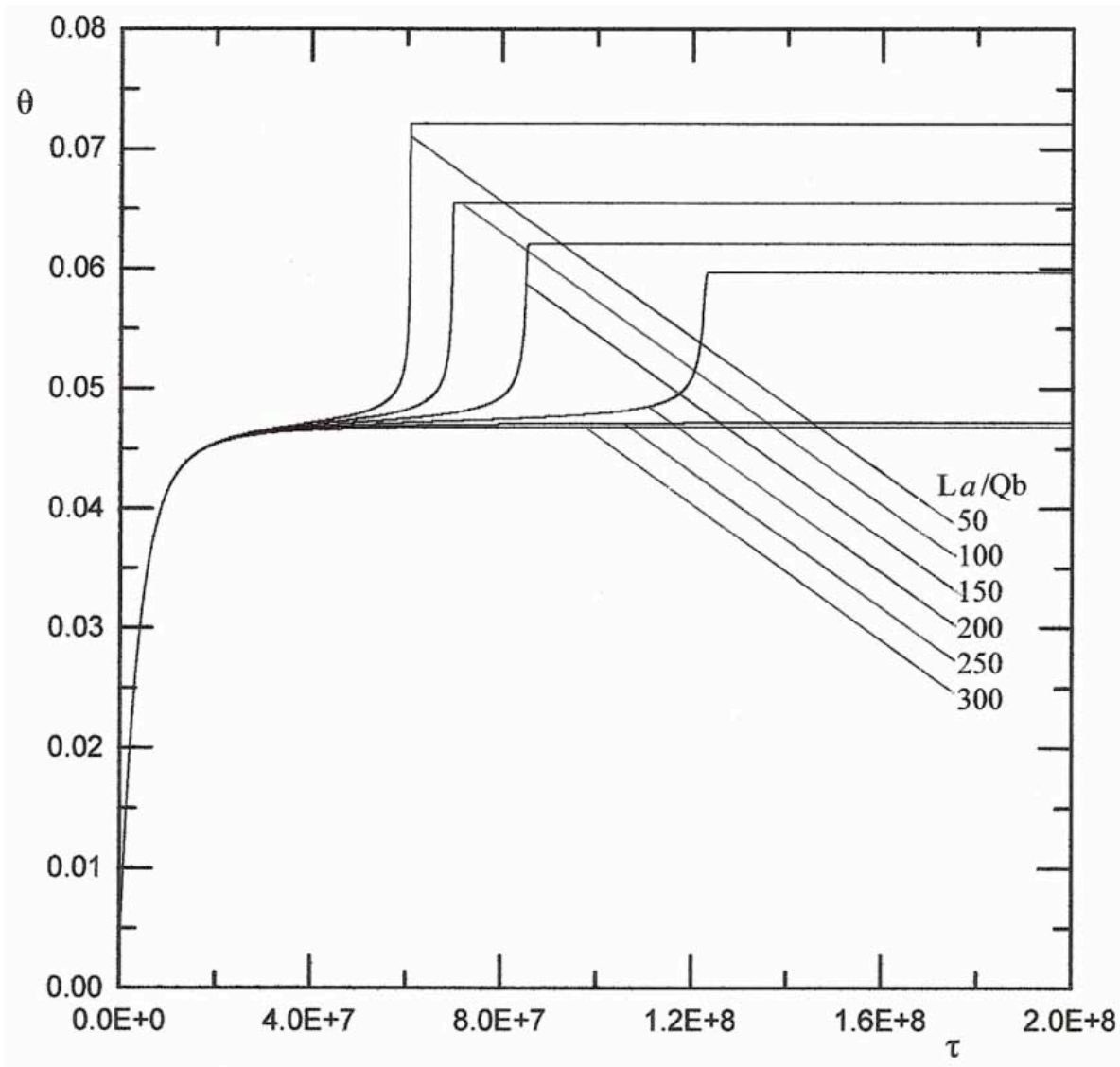

Fig. (10). $\theta-\tau$ trajectories for $\left(\mathrm{P}_{\mathrm{am}} / \mathrm{P}_{0}\right)=0.05,(\mathrm{~L} / \mathrm{E})=0.5, \theta 0=0.045, \psi=4000000$, and $(\mathrm{L} a / \mathrm{Qb})=50,100,150,200,250$, and 300 .

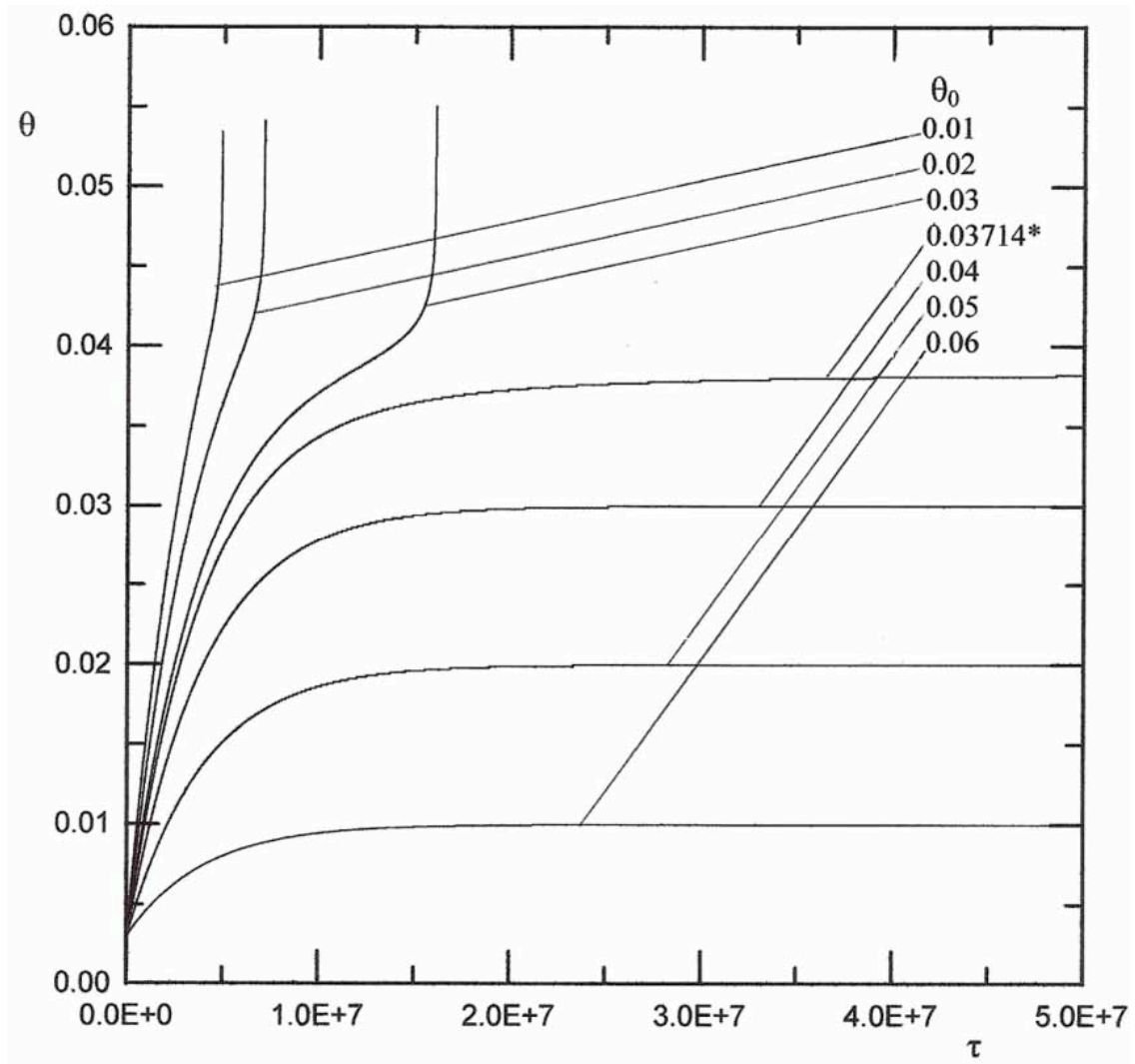

Fig. (11). $\theta-\tau$ trajectories for $\psi=4000000,(\mathrm{~L} a / \mathrm{Qb})=50,(\mathrm{~L} / \mathrm{E})=0.06,\left(\mathrm{P}_{\mathrm{am}} / \mathrm{P}_{0}\right)=0.06$, and $\theta_{0}=0.01,0.02,0.03,0.03714,0.04,0.05$, and 0.06 . 


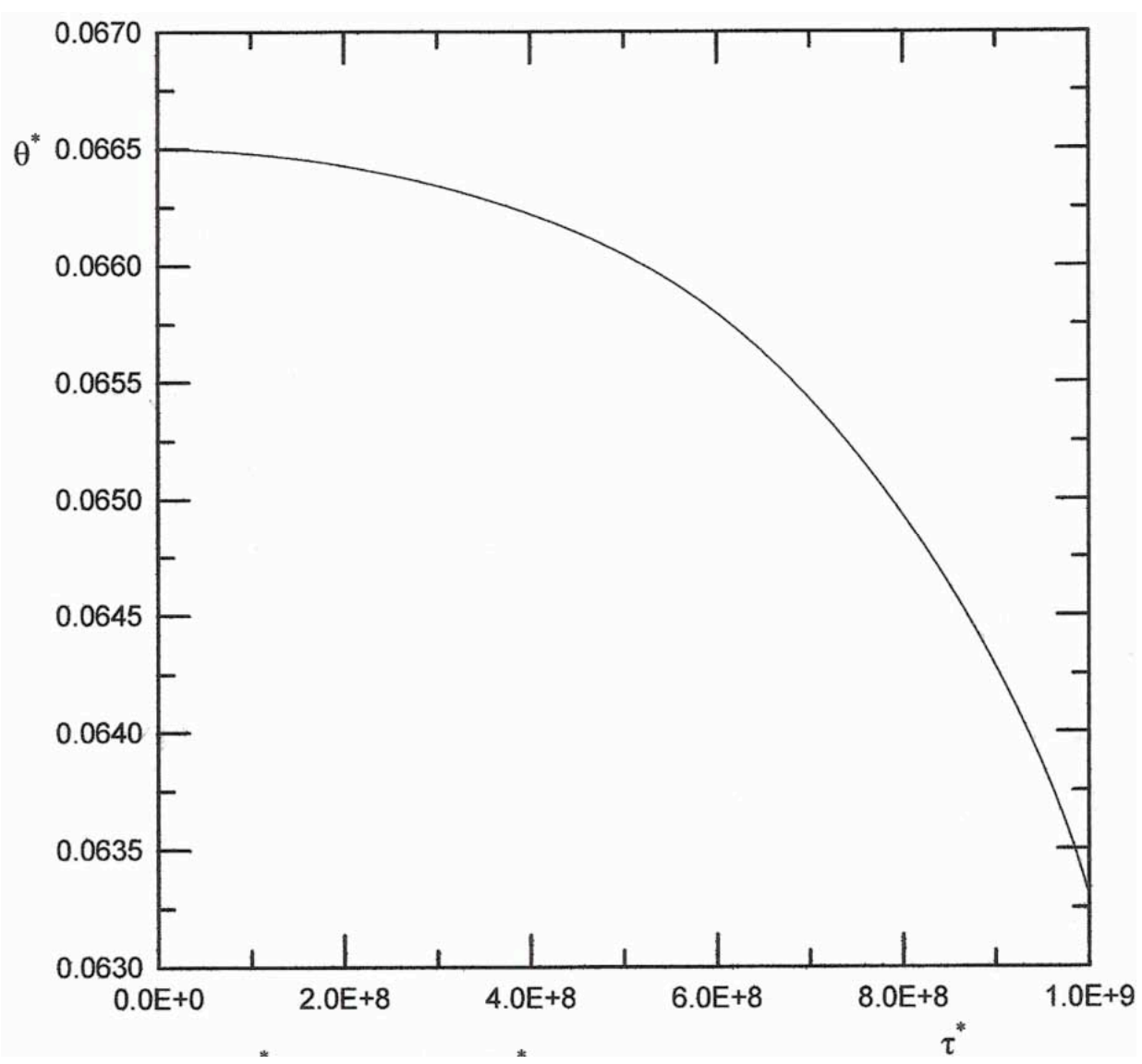

Fig. (12). $\theta^{*}$ as a function of $\tau^{*}$.

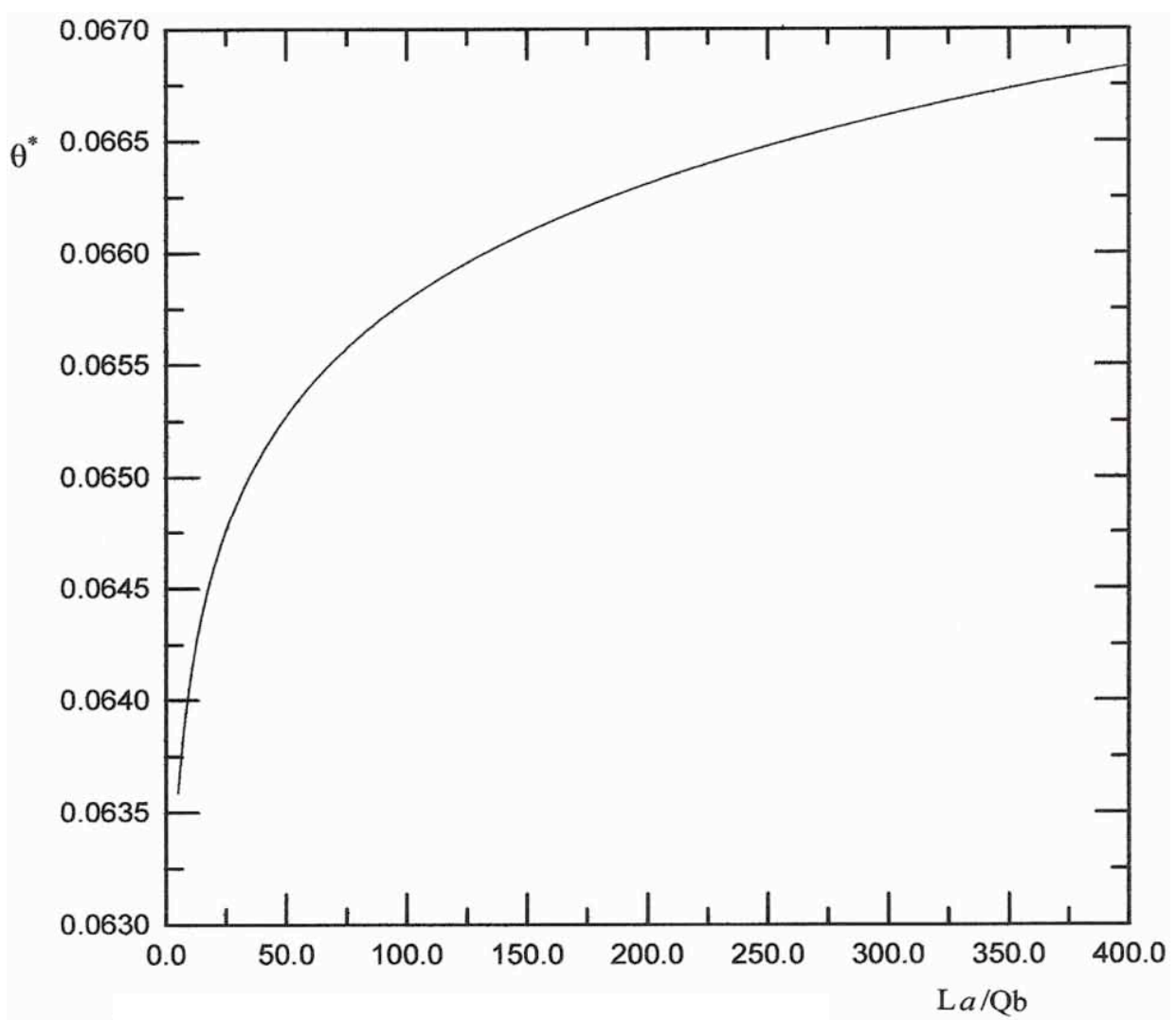

Fig. (13). $\theta^{*}$ as a function of $(\mathrm{L} a / \mathrm{Qb})$. 


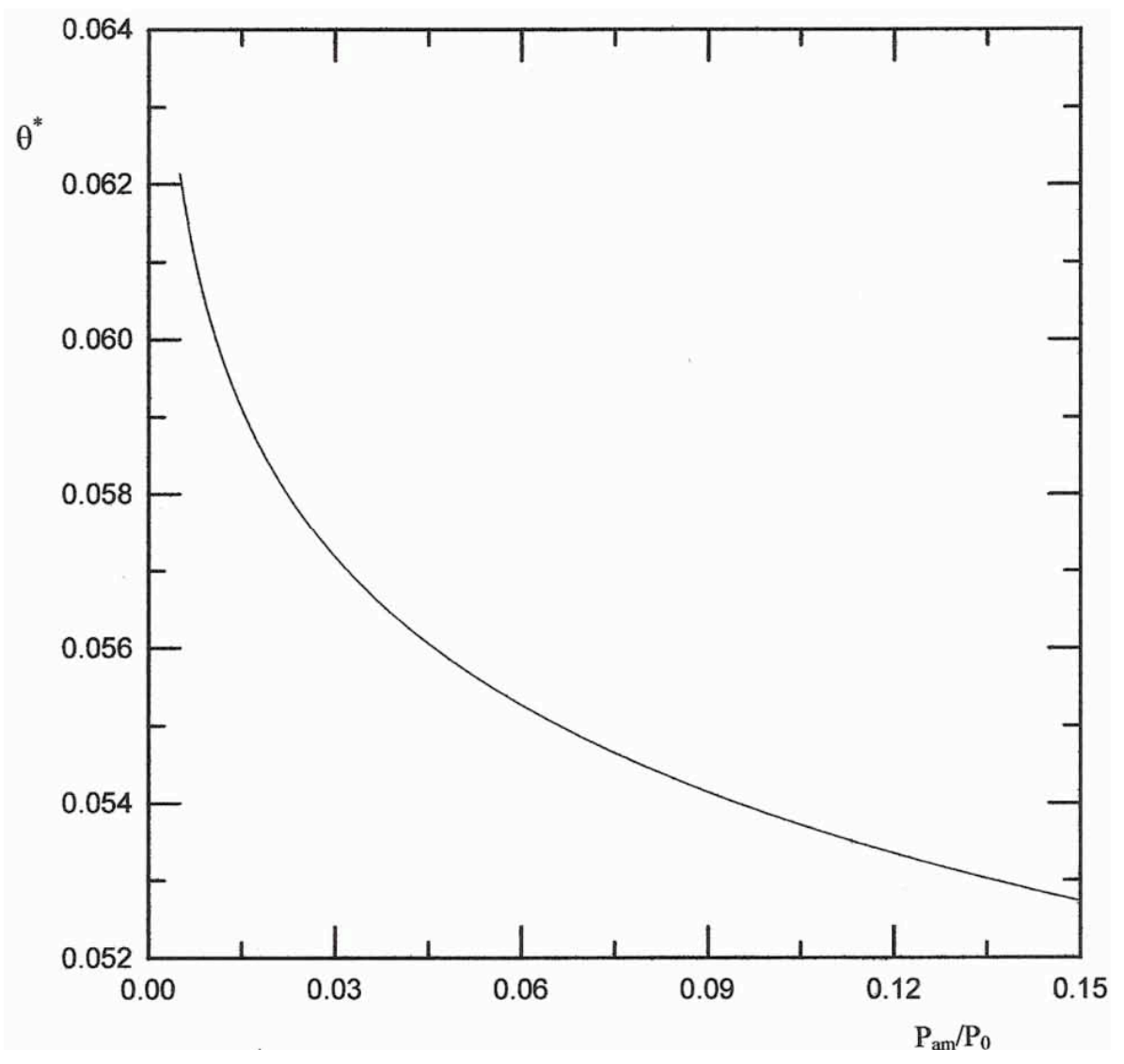

Fig. (14). $\theta^{*}$ as a function of $\left(\mathrm{P}_{\mathrm{am}} \cdot \mathrm{P}_{0}\right)$.

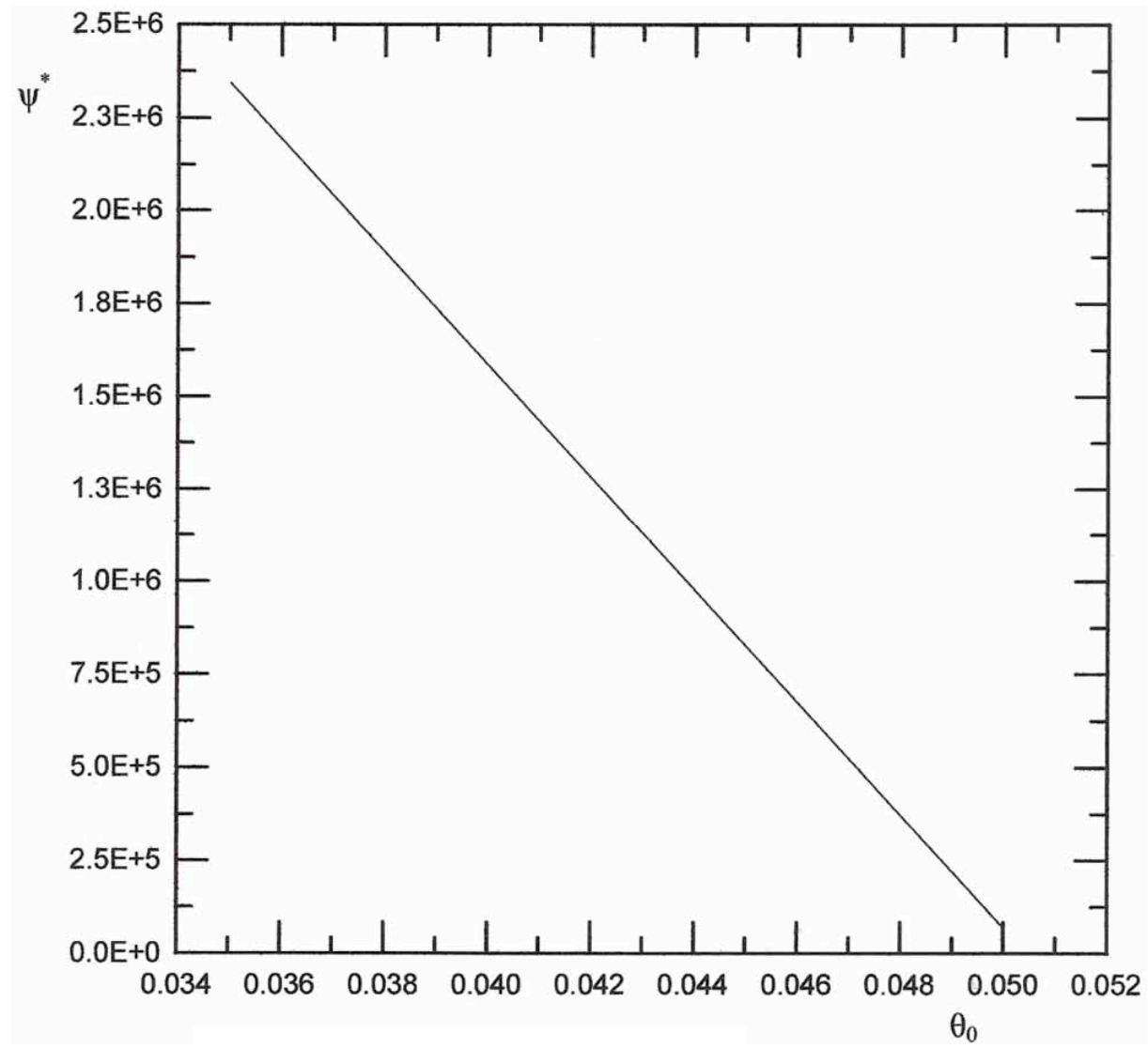

Fig. (15). $\psi^{*}$ as a function of $\theta_{0}$. 


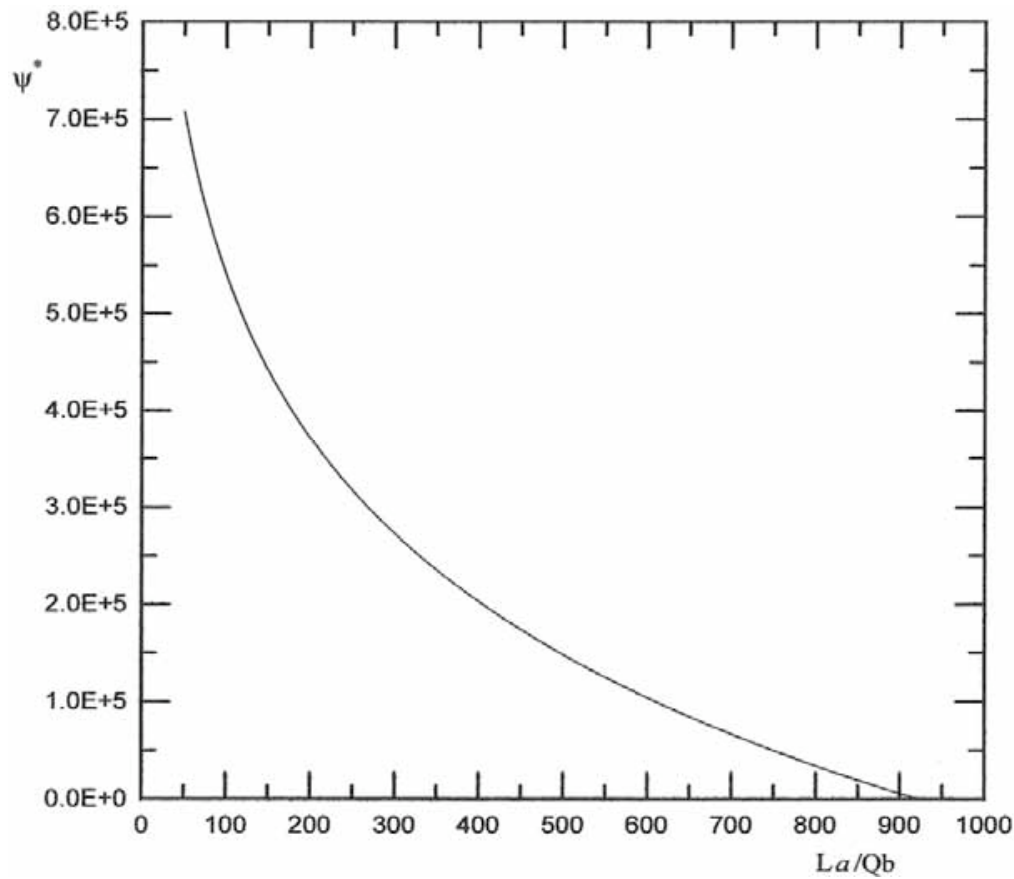

Fig. (16). $\psi^{*}$ as a function of $(\mathrm{L} a / \mathrm{Qb})$.

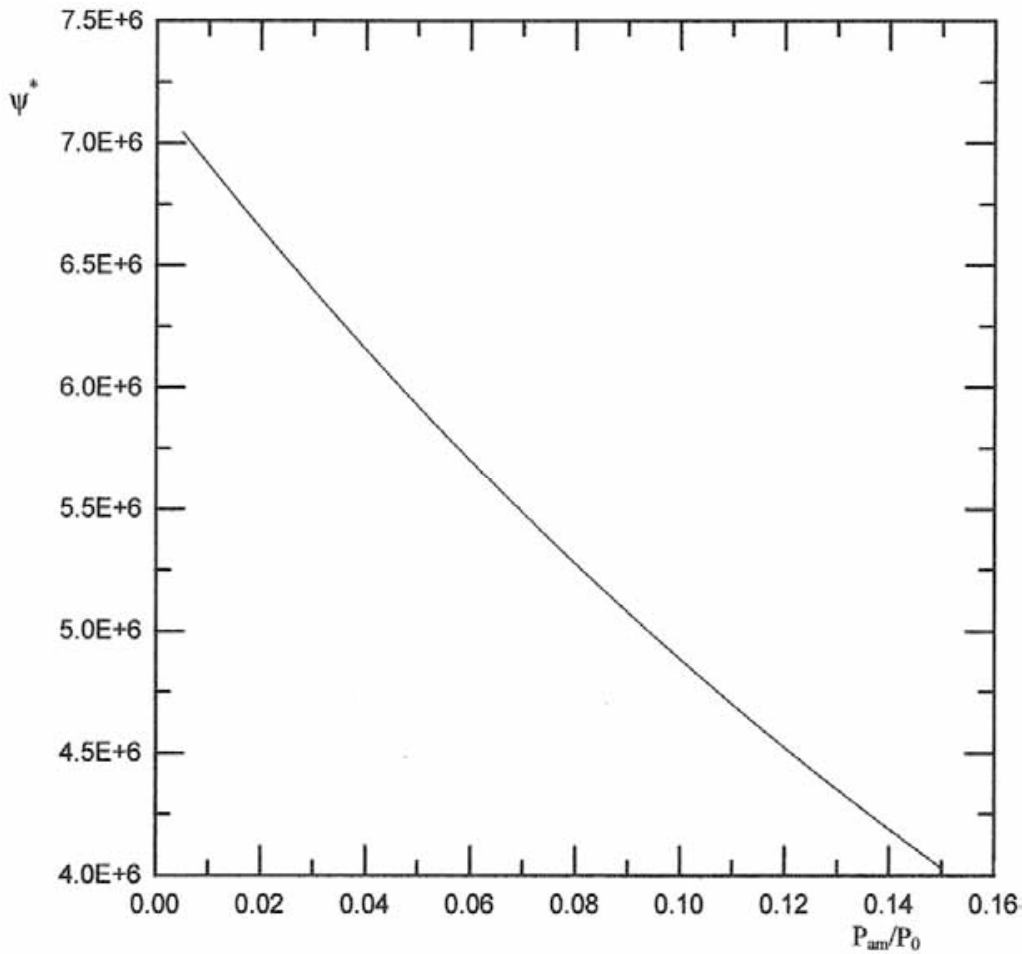

Fig. (17). $\psi^{*}$ as a function of $\left(\mathrm{P}_{\mathrm{am}} \cdot \mathrm{P}_{0}\right)$

4. The relationships between the critical modified Semenov number and the critical modified FrankKamnentskii number of both volatile and non-volatile energetic materials are offered.

5. At high pressure $\left(P_{a m}\right)$ and low temperature, heat losses due to the volumetric evaporation are negligible and the material behaves as a nonvolatile substance. As the temperature is increased (or the pressure is decreased), the effect of volatility increases, resulting in a decrease in the total thermal effect as shown from the analytical solution.

6. The numerical solution of the integral equation (2) produces the critical parameters $\psi^{*}, \theta^{*}, \tau^{*}$ as a function of the different parameters as shown in Figs. (12 to 18). Figures show that high $\theta^{*}$ occurs at low $\tau^{*}$ and vice versa. It can see that as the initial temperature $\theta_{0}$ increases, $\theta^{*}$ increases and $\psi^{*}$ decreases. It can also be seen that as a value of 


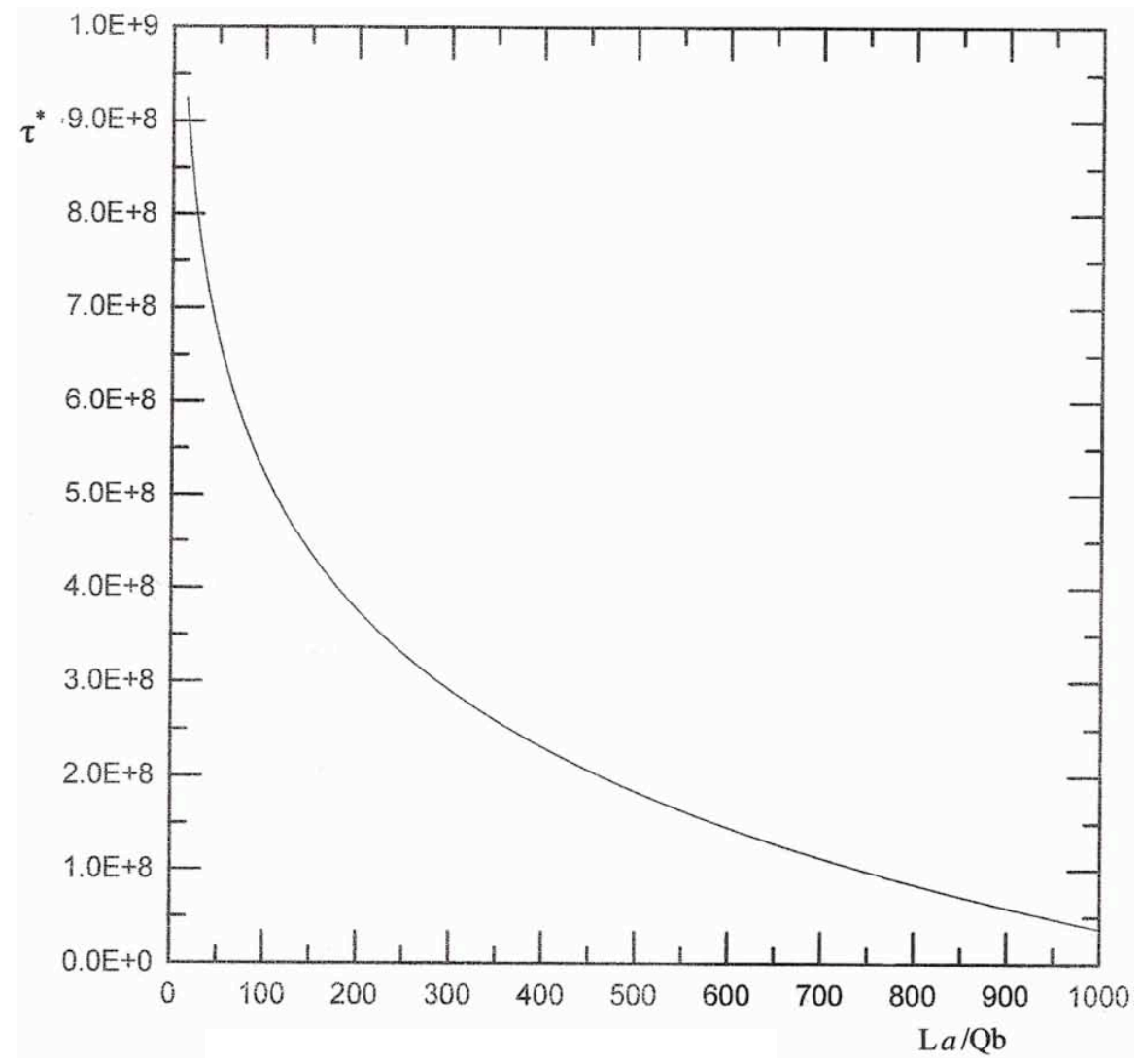

Fig. (18). $\tau^{*}$ as a function of $(\mathrm{L} a / \mathrm{Qb})$.

(Lb/Q $a)$ starting from zero (nonvolatile liquid) increases, $\theta^{*}$ increases and $\psi^{*}$ decreases. $\theta_{0}$ shows inversely proportional with $\psi^{*}$. Lower values of $\left(\mathrm{P}_{\mathrm{am}} / \mathrm{P}_{0}\right)$ produce high values of $\theta^{*}$ and vice versa.

7. Also, lower values of $(\mathrm{Lb} / \mathrm{Q})$ or $(\mathrm{L} / \mathrm{E})$ produce high values of $\tau^{*}$ and vice versa. These numerical results coincide with results obtained from the analytical solutions.

\section{NOMENCLATURE}

$\mathrm{A}_{0}$ frequency factor of the reaction, $\mathrm{s}^{-1}$

$a$ moles number of liquid in the decomposition reaction.

b moles number of gas formation during the decomposition reaction of liquid

c heat capacity of the liquid, $\mathrm{kJ} / \mathrm{kg} \mathrm{K}$.

E activation energy of the reaction, $\mathrm{kJ} / \mathrm{kg}$

$\mathrm{h}$ heat transfer coefficient, $\mathrm{W} / \mathrm{m}^{2} \mathrm{~K}$

L latent evaporation heat, $\mathrm{kJ} / \mathrm{kg}$

L/E dimensionless latent evaporation heat

$\mathrm{P}_{\mathrm{am}}$ pressure in the gas bubble $=$ ambient pressure where $\mathrm{P}_{\mathrm{v}}+\mathrm{P}_{\mathrm{g}}=\mathrm{P}_{\mathrm{am}}$

$\mathrm{P}_{0}$ pre-exponential factor in the expression for the saturated vapor pressure $\left(\mathrm{P}_{\mathrm{v}}\right)$ of the liquid

expression where $\mathrm{P}_{\mathrm{v}}=\mathrm{P}_{0} \exp (-\mathrm{L} / \mathrm{RT})$

$\mathrm{Q}$ heat of decomposition of the liquid, $\mathrm{kJ}$
Lb/Qa dimensionless thermal effect

$\mathrm{R}$ gas constant, $\mathrm{kJ} / \mathrm{kg} \mathrm{K}$

$\mathrm{S}$ heat-exchange surface area, $\mathrm{m}^{2}$

$\mathrm{T}$ temperature, $\mathrm{K}$

$\mathrm{T}_{0}$ ambient (thermostat) temperature, $\mathrm{K}$

$\mathrm{V}$ volume of the liquid, $\mathrm{m}^{3}$

\section{GREEK SYMBOLS}

$\theta=\mathrm{RT} / \mathrm{E}$, dimensionless temperature

$\rho=$ density of liquid, $\mathrm{kg} / \mathrm{m}^{3}$

$\tau=\mathrm{QA}_{0} \mathrm{Rt} / \mathrm{c} \rho \mathrm{E}$, dimensionless time

$\psi=\mathrm{RQA}_{0} \mathrm{~V} / \mathrm{hSE}$, modified Semenov number

\section{SUBSCRIPT AND SUPERSCRIPT}

ad adiabatic condition

m maximum condition

*critical condition

\section{CONFLICT OF INTEREST}

The author confirm that this article content has no conflicts of interest.

\section{ACKNOWLEDGEMENT}

Declared none. 


\section{REFERENCES}

[1] A.G. Merzhanov, B.M. Slutsker, and A.S. Shteinberg. "Thermal decomposition and thermal explosion of volatile explosives". Combustion Explosion Shock Waves J., vol. 4, pp. 312-316, 1968.

[2] Merzhanov A.G., Dubovitzkii F.I. "Modern state of thermal explosion theory". Usp. Khim., vol. 35, no. 4, pp.656-683, 1966.

[3] N.G. Samoylenko, A.A. Vinokurov, V.G. Abramov, and A.G. Merzhanov, "Investigation of kinetics for dinitroxydiethylnitramine thermal decomposition in absence of gas outlet from the reaction zone". Rus. J. Phys. Chem., vol. 44, p. 22, 1970.

[4] G.K. Williams, and T.B. Brill, "Thermal decomposition of energetic materials. 68. Decomposition and sublimation kinetic of NTO and evaluation prior kinetic data", J. Phys. Chem., Vol. 99, no. 33, pp. 12536-12539, 1995.

[5] G.K. Williams, and T.B. Brill, "Thermal decomposition of energetic materials. 70. Kinetic of organic peroxide decomposition derived from the filament control voltage of T-Jump/FT-IR spectroscopy”, Appl. Spectro., vol. 51, no. 3, pp. 423-427, 1997.

[6] S. Gurdip, and S.P Felix, "Studies on energetic compound: 25. An overview of preparation, thermoanalysis and applications of the salts of 5-Nitro-2, 4-dihydro-3H-1,2,4-triazol-3-one (NTO)", J. Hazard. Mater., vol. 90, no. 1, pp. 1-17, 2002.

[7] M.E. Brown, "Thermal analysis of energetic materials" Thermochimica Acta, vol. 148, pp. 521-531, 1989.

[8] C. Wei, W.J. Rogers, and M.S. Mannan, "Detection of the autocatalytic decomposition behavior of energetic materials using
APTAC", J. Thermal Anal Calorimetr., vol. 83, no. 1, pp. 125-130, 2006.

[9] L. Wang, H. Chen, T. Zhang, J. Zhang, and Li Yang, "Synthesis, characterization, thermal and explosive properties of potassium salts of trinitrephloroglucinol", J. Hazard. Mater., vol. 147, no. 1-2, pp. 576-580, 2007.

[10] A.A. Belyaev, Z.I. Kagarova, and B.V. Novozhilov, "A combustion of volatile condensed systems behind the stability limit of the stationary regime", Combustion Explosion Shock Waves J., vol. 40, no. 4, pp. 425-431, 2004.

[11] P. Chen, Zhao Feng-qi, H.U. Woyang, Rong-zu, Gao, Sheng-li, Zheng Yu-mei, Deng, Min-zhi, and Y. Gao, "The thermal behavior and kinetic parameter of the exothermic decomposition reaction of the title compound," Chem. Res. Chin. Univ., vol. 21, no. 1, pp. 100-103, 2005.

[12] A.S. Shteinberg, Fast reactions in energetic materials. Springer: Verlag Berlin: Heidelberg, 2008.

[13] J.C Lermant, and S. Yip, "Equivalence of the criticality condition for both The Semenov and the Frank-Kamentskii Problems", Combustion Flame J., vol. 57, pp. 41-54, 1984.

[14] J. Adler, and J.W. Enig, "The critical conditions in thermal explosion theory with reactant consumption", Combustion Flame J., vol. 8, pp. 97-102, 1964.

[15] A. Shouman, and A.S. El-Sayed, "Accounting for reactant consumption in the thermal explosion problem III. Criticality conditions for the Arrhenius problem", Combustion Flame J., vol. 113, pp. 212-233, 1998.

CC Saad A. EL-Sayed; Licensee Bentham Open.

This is an open access article licensed under the terms of the Creative Commons Attribution Non-Commercial License (http://creativecommons.org/licenses/ by-nc/3.0/) which permits unrestricted, non-commercial use, distribution and reproduction in any medium, provided the work is properly cited. 